\title{
Phosphorylation of $\mathrm{Na}^{+}, \mathrm{K}^{+}$-ATPase at Tyr10 of the a1-Subunit is Suppressed by AMPK and Enhanced by Ouabain in Cultured Kidney Cells
}

\author{
Metka Petrič ${ }^{1}$ D $\cdot$ Anja Vidović ${ }^{1} \cdot$ Klemen Dolinar $^{1} \cdot$ Katarina Miš $^{1} \cdot$ Alexander V. Chibalin $^{2,3}$ (D) Sergej Pirkmajer $^{1}$ (D)
}

Received: 27 July 2021 / Accepted: 27 October 2021 / Published online: 8 November 2021

(c) The Author(s) 2021

\section{Abstract}

$\mathrm{Na}^{+}, \mathrm{K}^{+}$-ATPase (NKA) is essential for maintenance of cellular and whole-body water and ion homeostasis. In the kidney, a major site of ion transport, NKA consumes $\sim 50 \%$ of ATP, indicating a tight coordination of NKA and energy metabolism. AMP-activated protein kinase (AMPK), a cellular energy sensor, regulates NKA by modulating serine phosphorylation of the $\alpha 1$-subunit, but whether it modulates other important regulatory phosphosites, such as Tyr10, is unknown. Using human kidney (HK-2) cells, we determined that the phosphorylation of Tyr10 was stimulated by the epidermal growth factor (EGF), which was opposed by inhibitors of Src kinases (PP2), tyrosine kinases (genistein), and EGF receptor (EGFR, gefitinib). AMPK activators AICAR and A-769662 suppressed the EGF-stimulated phosphorylation of EGFR (Tyr1173) and NKA $\alpha 1$ at Tyr10. The phosphorylation of Src (Tyr416) was unaltered by AICAR and increased by A-769662. Conversely, ouabain $(100 \mathrm{nM})$, a pharmacological NKA inhibitor and a putative adrenocortical hormone, enhanced the EGF-stimulated Tyr10 phosphorylation without altering the phosphorylation of EGFR (Tyr1173) or Src (Tyr416). Ouabain (100-1000 nM) increased the ADP:ATP ratio, while it suppressed the lactate production and the oxygen consumption rate in a dose-dependent manner. Treatment with ouabain or gene silencing of NKA $\alpha 1$ or NKA $\alpha 3$ subunit did not activate AMPK. In summary, AMPK activators and ouabain had antagonistic effects on the phosphorylation of NKA $\alpha 1$ at Tyr10 in cultured HK-2 cells, which implicates a role for Tyr10 in coordinated regulation of NKA-mediated ion transport and energy metabolism.

\section{Graphical Abstract}

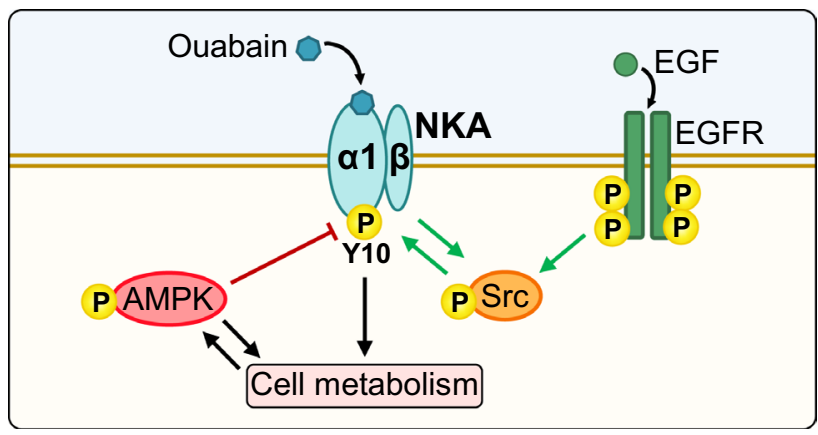

Keywords AMPK $\cdot$ Ouabain $\cdot$ Tyr10 $\cdot \mathrm{Na}^{+}, \mathrm{K}^{+}$-ATPase $\cdot \mathrm{EGF} \cdot \mathrm{HK}-2$ cells

Alexander V. Chibalin

alexander.chibalin@ki.se

Sergej Pirkmajer

sergej.pirkmajer@mf.uni-lj.si

Extended author information available on the last page of the article

\section{Introduction}

$\mathrm{Na}^{+}, \mathrm{K}^{+}$-ATPase (NKA), also known as $\mathrm{Na}-\mathrm{K}$ pump, is essential for the cellular as well as the whole-body water and ion homeostasis (Rossier et al. 2015; Skou 1957, 1998). 
NKA, which comprises a catalytic $\alpha$-subunit (isoforms $\alpha 1-4$ ) and a glycoprotein $\beta$-subunit (isoforms $\beta 1-3$ ) (Blanco and Mercer 1998; Craig and Kyte 1980; Kyte 1971; Morth et al. 2007), consumes one ATP to pump two $\mathrm{K}^{+}$ions into and three $\mathrm{Na}^{+}$ions out of the cell (Post and Jolly 1957; Sen and Post 1964), thus maintaining ion concentrations, cell excitability, as well as the driving force for the $\mathrm{Na}^{+}$-driven secondary transport of nutrients, such as glucose. The abundance of NKA is especially high in the kidney (Buffin-Meyer et al. 1997; El Mernissi and Doucet 1984), which preserves the balance between the intake and loss of water and ions, while preventing urinary loss of glucose and other nutrients (Feraille and Dizin 2016; Feraille and Doucet 2001). The kidney consumes $~ 50 \%$ of ATP for energizing NKA (Clausen et al. 1991; Rolfe and Brown 1997), not least in the proximal tubules, which represent $\sim 12 \%$ of the total ATP consumption in the kidney (Ferrannini 2017). In diabetes mellitus the proximal tubules reabsorb a markedly increased load of glucose and other solutes, which further increases ATP consumption by NKA (Ferrannini 2017). Clearly, a coordinated regulation of NKA and energy metabolism is required to maintain homeostasis.

AMP-activated protein kinase (AMPK), a serine/threonine kinase, is a cellular energy sensor, important regulator of energy metabolism (Hardie 2018), and a leading experimental target for treatment of type 2 diabetes (Hardie 2013; Steinberg and Carling 2019), diabetic nephropathy, as well as polycystic kidney disease (Rajani et al. 2017). Once activated by an increase in the AMP:ATP and/or the ADP:ATP ratio, AMPK stimulates the ATP-generating catabolic and suppresses the ATP-consuming anabolic pathways, which helps to restore the energy balance under energy-deprived conditions. As well as the metabolic pathways, AMPK regulates phosphorylation of ion channels and transporters (Lang and Foller 2014; Rajani et al. 2017), including NKA (Pirkmajer et al. 2021), and therefore provides a direct link between regulation of ion transport and energy metabolism. AMPK regulates endocytosis of NKA by indirectly modulating the phosphorylation of the NKA $\alpha 1$-subunit (NKA $\alpha 1$ ) at Ser18 (aka Ser23) (Fig. 1) (Benziane et al. 2012). However, NKA $\alpha 1$ has other important phosphosites that might be modulated by AMPK.

Tyrosine phosphorylation of NKA 1 in the proximal kidney tubules is stimulated by insulin and epidermal growth factor (EGF) (Feraille et al. 1997). Among the phosphorylatable tyrosine residues, Tyr10 is particularly important not only because its phosphorylation is essential for the insulin-induced activation of NKA in the kidney tubules (Feraille et al. 1999), but also because it is conserved across the vertebrate species (Fig. 1). Aside from insulin, ouabain, a widely used pharmacological inhibitor of NKA and a putative adrenocortical hormone, was shown to increase phosphorylation of NKA $\alpha 1$ at Tyr10 in

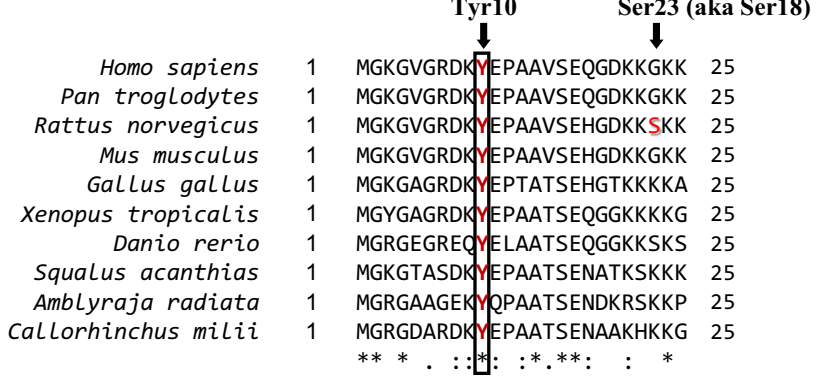

Fig. 1 Tyr10 residue and surrounding amino acid sequence on the $\mathrm{N}$ terminus of $\alpha 1$-subunit of NKA are well-conserved in jawed vertebrates (Gnathostomata). The Ser23 (aka Ser18) residue is present in the rat NKA $\alpha 1$-subunit. Alignments of $\mathrm{N}$ terminus of $\alpha 1$-subunit of NKA among different species of Gnathostomata: Homo sapiens (human), Pan troglodytes (chimpanzee), Rattus norvegicus (brown rat), Mus musculus (house mouse), Gallus gallus (red junglefowl), Danio rerio (zebrafish), Squalus acanthias (spiny dogfish), Amblyraja radiata (thorny skate) and Callorhinchus milii (elephant shark) using Clustal Omega alignment program. Conservation scheme: [*] single, fully conserved residue, [:] strongly similar residues, [.] weakly similar residues

cultured kidney cells (Holthouser et al. 2010). As demonstrated in nonpigmented ciliary epithelial cells of the eye, the Tyr 10 phosphorylation is increased also by nitric oxide (Shahidullah et al. 2014). Moreover, eplerenone, an antagonist of the aldosterone receptor, induced the dephosphorylation of Tyr10 in rat diaphragm muscle ex vivo (Breitenbach et al. 2016), which again suggests that Tyr10 plays an important role in hormonal regulation of NKA.

Tyrosine phosphorylation of NKA $\alpha$ is catalysed by the non-receptor tyrosine kinases from the Src family, such as Src (Al-Khalili et al. 2003) and Lyn (Bozulic et al. 2004a). Importantly, Src is a downstream effector of EGF receptor (EGFR) as well as ouabain. Binding of ouabain to NKA does not only inhibit its pumping but also activates multiple signalling pathways, including the EGFR-Src-ERK1/2 pathway (Aperia et al. 2016; Bagrov et al. 2009; Blaustein and Hamlyn 2020; Schoner and Scheiner-Bobis 2007; Xie and Askari 2002). Activation of Src might therefore provide a direct link between EGF, ouabain, and increased phosphorylation of Tyr 10. Conversely, AMPK was shown to suppress the activation of the EGFR in cancer cells (Jhaveri et al. 2015), which indirectly suggests that AMPK may suppress the phosphorylation of Tyr10.

We examined whether and how EGF, AMPK, and ouabain modulated the phosphorylation of NKA $\alpha 1$ at Tyr10 in HK-2 cells, an epithelial cell line obtained from the proximal tubules of normal adult human kidney (Ryan et al. 1994). Our main finding was that pharmacological AMPK activators suppressed and ouabain enhanced the EGF-stimulated phosphorylation of Tyr10. Our results 
implicate a role for AMPK and ouabain in regulation of tyrosine phosphorylation of NKA.

\section{Materials and Methods}

\section{Materials}

Immortalized proximal tubule epithelial cell line HK-2 was from ATCC. Cell culture flasks and plates were from Sarstedt and TPP. Dulbecco's Modified Eagle Medium (DMEM), foetal bovine serum (FBS, No. 10270-106), Pen Strep $(5000 \mathrm{U} / \mathrm{mL}$ of penicillin and $5000 \mu \mathrm{g} / \mathrm{mL}$ of streptomycin) and TaqMan Universal MasterMix and TaqMan gene expression assays were from Thermo Fisher Scientific. 4-12\% Criterion XT Bis-Tris polyacrylamide gels and XT MES electrophoresis buffer were from Bio-Rad. PCR plates and PCR plate adhesive films were from Bio-Rad or Nippon Genetics. Amersham ECL Full-Range Rainbow Molecular Weight Markers were from GE Healthcare Life Sciences. Polyvinylidene difluoride (PVDF) membranes and all other reagents, unless specified otherwise, were from Merck.

\section{HK-2 Cell Cultures}

HK-2 cell line was grown in DMEM GlutaMAX ( $1 \mathrm{~g} / \mathrm{L}$ glucose, pyruvate) supplemented with $10 \%$ FBS and $1 \%$ Pen Strep at $37{ }^{\circ} \mathrm{C}$ in humidified air with $5 \% \mathrm{CO}_{2}$ up until the passage 10. A day prior experiment the cells were seeded on 6 -well cell culture plates at density of $2 \times 10^{5}$ cells/well or on 12 -well cell culture plates at density of $1 \times 10^{5}$ cells/well (unless specified otherwise) to obtain 100\% confluency at the time of experiment. For the last $4 \mathrm{~h}$ the cells were serumstarved in DMEM without serum and antibiotics.

\section{Treatments}

The following substances were used for the treatment of the cells: activators of AMPK 5-aminoimidazole-4-carboxamide 1- $\beta$-D-ribofuranoside (AICAR; No. 10010241, Cayman Chemical) and A-769662 (No. 1466, Axon Medchem), mitochondrial oxidative phosphorylation uncoupler carbonyl cyanide-4-(trifluoromethoxy)phenylhydrazone (FCCP; No. C2920, Merck), inhibitor of Src kinases 3-(4-chlorophenyl)1-(1,1-dimethylethyl)-1H-pyrazolo[3,4-d]pyrimidin4-amine (PP2; No. 13198, Cayman Chemical), inhibitor of ATP synthase oligomycin (No. 495455, Merck), insulin (Actrapid, NovoNordisk), $\mathrm{Na}^{+}, \mathrm{K}^{+}$-ATPase inhibitor ouabain (No. O3125, Merck), epidermal growth factor (EGF; No. E9644, Merck), EGFR tyrosine kinase inhibitor gefitinib (No. 13166, Cayman Chemical), tyrosine kinase inhibitor genistein (No. 10005167, Cayman Chemical), electron transport chain complex I inhibitor rotenone (No. 557368,
Merck), and complex III inhibitor antimycin A (No. A8674, Merck).

\section{Immunoblotting}

Immunoblotting was performed as described (Dolinar et al. 2018; Mars et al. 2020; Pirkmajer et al. 2020). At the end of experiment, the cells were immediately transferred to ice and washed 2-times in ice-cold PBS $(137 \mathrm{mM} \mathrm{NaCl}, 2.7 \mathrm{mM}$ $\mathrm{KCl}, 10 \mathrm{mM} \mathrm{Na}_{2} \mathrm{HPO}_{4}, 1.8 \mathrm{mM} \mathrm{KH}_{2} \mathrm{PO}_{4}, \mathrm{pH}$ 7.4). Cells were lysed with Laemmli buffer $(62.5 \mathrm{mM}$ Tris- $\mathrm{HCl}(\mathrm{pH}$ 6.8 ), $2 \%$ (wt/vol) sodium dodecyl sulphate (SDS), $10 \%$ (wt/ vol) glycerol, $5 \%$ (vol/vol) 2-mercaptoethanol, $0.002 \%$ (wt/ vol) bromophenol blue) and were subsequently sonicated and heated at $56{ }^{\circ} \mathrm{C}$ for $20 \mathrm{~min}$. Proteins were separated by SDS polyacrylamide gel electrophoresis with $4-12 \%$ gels and transferred to the PVDF membranes with wet electrotransfer. After the transfer, membranes were stained with Ponceau S [0.1\% (wt/vol) in 5\% (vol/vol) acetic acid] to evaluate uniformity of sample protein concentration. Membranes were then blocked in $7.5 \%$ (wt/vol) dry skimmed milk in Tris-buffered saline with Tween (TBST; $20 \mathrm{mM}$ Tris, $150 \mathrm{mM} \mathrm{NaCl}, 0.02 \%$ (vol/vol) Tween $20, \mathrm{pH} 7.6$ ) for $1 \mathrm{~h}$ at room temperature, washed several times in TBST and then incubated with appropriate primary antibody (see Table 1) in primary antibody buffer $(20 \mathrm{mM}$ Tris, $150 \mathrm{mM} \mathrm{NaCl}, \mathrm{pH}$ $7.6,0.1 \%(\mathrm{wt} / \mathrm{vol})$ bovine serum albumin and $0.1 \%(\mathrm{wt} / \mathrm{vol})$ sodium azide) overnight at $4{ }^{\circ} \mathrm{C}$. The next day membranes were washed in TBST and incubated with appropriate secondary antibody conjugated to the horseradish peroxidase (HRP, Bio-Rad) with 5\% dry skimmed milk in TBST for $1 \mathrm{~h}$ at room temperature and washed with TBST. Finally, the membranes were incubated with chemiluminescence substrate (Pierce ECL Western Blotting Substrate, Thermo Fisher Scientific or, for weaker detection, Clarity Max ECL, Bio-Rad) for $1 \mathrm{~min}$. The proteins were visualized on x-ray films (CP-BU NEW, AGFA HealthCare) which were scanned with GS-800 Densitometer (Bio-Rad) or imaged with FUSION FX6 (Vilber). Protein bands were quantified with Quantity One 1-D Analysis Software (4.6.9., Bio-Rad). Intensities of individual bands are presented relative to the total intensity of all the bands for each replicate.

\section{Gene Silencing}

HK-2 cells were seeded on 6-well cell culture plates at density of $1 \times 10^{5}$ cells/well a day prior transfection to achieve $80 \%$ confluency at the time of transfection. For the last $6 \mathrm{~h}$ the cells were grown in medium without antibiotics. The cells were transfected with siRNA against human $\mathrm{Na}^{+}, \mathrm{K}^{+}$-ATPase $\alpha 1$ mRNA (ATP1A1, No. L-006111-000005 ) or human $\mathrm{Na}^{+}, \mathrm{K}^{+}$-ATPase $\alpha 3$ mRNA (ATP1A3, No. J-004614-00-0005) (both ON-TARGETplus-SMARTpool 
Table 1 Antibodies used for immunoblot and immunoblot protocol details

\begin{tabular}{|c|c|c|c|c|c|}
\hline Primary antibody & Species & Dilution & Cat. No & $\begin{array}{l}\text { Secondary } \\
\text { antibody }\end{array}$ & Dilution \\
\hline Phospho-ACC (Ser79) & Rabbit pAb & $1: 1,000$ & \#3661, CST & GAR & $1: 15,000$ \\
\hline Total ACC & Rabbit mAb & $1: 1,000$ & \#3676, CST & GAR & $1: 15,000$ \\
\hline Actin & Rabbit pAb & $1: 1,500$ & \#sc-1616-R, SCB & GAR & $1: 30,000$ \\
\hline Phospho-Akt (Ser473) & Rabbit mAb & $1: 2,000$ & \#4060, CST & GAR & $1: 15,000$ \\
\hline Phospho-AMPK $\alpha$ (Thr172) & Rabbit mAb & $1: 1,000$ & \#2535, CST & GAR & $1: 10,000$ \\
\hline Caspase-3 & Rabbit pAb & $1: 1,000$ & \#9662, CST & GAR & $1: 20,000$ \\
\hline Phospho-EGFR (Tyr1173) & Rabbit mAb & $1: 1,000$ & \#4407, CST & GAR & $1: 10,000$ \\
\hline Total EGFR & Rabbit pAb & $1: 1,000$ & \#2232, CST & GAR & $1: 20,000$ \\
\hline Phospho-ERK1/2 (Thr202/Tyr204) & Rabbit mAb & $1: 20,000$ & \#4370, CST & GAR & $1: 20,000$ \\
\hline Total ERK1/2 & Rabbit mAb & $1: 1,000$ & \#4695, CST & GAR & $1: 20,000$ \\
\hline Phospho-NKA $\alpha 1$ (Tyr10) mAb & Rabbit mAb & $1: 500$ & \#13566, CST & GAR & $1: 10,000$ \\
\hline Phospho-NKA $\alpha 1$ (Tyr10) pAb & Rabbit pAb & $1: 1,000$ & \#3060, CST & GAR & $1: 10,000$ \\
\hline Total NKA $\alpha 1$ (Ab1) & Mouse mAb & $1: 2,000$ & \#05-369, Merck & GAM & $1: 25,000$ \\
\hline Total NKA $\alpha 1(\mathrm{Ab} 2)$ & Rabbit mAb & $1: 1,000$ & \#23565, CST & GAR & $1: 20,000$ \\
\hline Phospho-Src (Tyr416) & Rabbit pAb & $1: 1,000$ & \#2101, CST & GAR & $1: 10,000$ \\
\hline Phospho-Src (Tyr527) & Rabbit pAb & $1: 1,000$ & \#2105, CST & GAR & $1: 15,000$ \\
\hline Total Src & Rabbit mAb & $1: 1,000$ & \#2123, CST & GAR & $1: 25,000$ \\
\hline
\end{tabular}

$A C C$ acetyl-CoA carboxylase, Akt protein kinase $\mathrm{B}, A M P K$ AMP-activated protein kinase, EGFR epidermal growth factor receptor, ERK1/2 p44/42 mitogen-activated protein kinases (MAPK), NKA $\mathrm{Na}^{+}, \mathrm{K}^{+}$-ATPase, $p A b$ polyclonal antibody, $m A b$ monoclonal antibody, CST Cell Signaling Technology, $S C B$ Santa Cruz Biotechnology, GAR goat anti-rabbit IgG-HRP conjugate \#1706515 (Bio-Rad), GAM goat anti-mouse IgG-HRP conjugate \#1706516 (Bio-Rad) from Horizon Discovery) using Invitrogen Lipofectamine 2000 Transfection Reagent (Thermo Fisher Scientific) according to the manufacturer's guidelines with siRNA in the final concentration of $5 \mathrm{nM}$. To test the off-target effects of siRNA, a non-targeting siRNA pool (ON-TARGET plus Non-targeting Pool, No. D-001810-10-20, Horizon Discovery) was used. After $24 \mathrm{~h}$ of transfection the medium was replaced with fresh DMEM (10\% FBS, without antibiotics/ siRNA) and the cells were incubated for another $24 \mathrm{~h}$. To enable measurement of lactate secretion into medium, the cells were grown in serum-free DMEM for the last $8 \mathrm{~h}$. The cells were washed with PBS and frozen at $-80{ }^{\circ} \mathrm{C}$ until further analysis. Gene knock-down was assayed using qPCR and immunoblot.

\section{qPCR}

Total RNA was isolated using RNeasy Plus Mini Kit (Qiagen) or E.Z.N.A. HP Total RNA Kit (Omega Bio-tek) and reverse transcribed to cDNA with High-Capacity cDNA Reverse Transcription Kit (Thermo Fisher Scientific). Quantitative real-time polymerase chain reaction (qPCR) was performed on 7500 Real-Time PCR System (Applied Biosystems, Thermo Fisher Scientific) using TaqMan Universal MasterMix and TaqMan gene expression assays for human $\alpha 1$-subunit of $\mathrm{Na}^{+}, \mathrm{K}^{+}$-ATPase (No. Hs00167556 $\mathrm{m} 1$ ) and human $\alpha 3$-subunit of $\mathrm{Na}^{+}, \mathrm{K}^{+}$-ATPase (No.
Hs00958036_m1). Expression of target gene was normalized to expression of cyclophilin (PPIA, No. Hs99999904_m1), which was used as an endogenous control. Efficiency of PCR was estimated with LinRegPCR software (2018.0) (Ramakers et al. 2003; Ruijter et al. 2009; Tuomi et al. 2010).

\section{Analysis of Extracellular Acidification Rate (ECAR) and Oxygen Consumption Rate (OCR)}

ECAR and OCR were analysed with Seahorse XFe24 Analyzer (Agilent). Cells were seeded on Seahorse XF24 cell culture microplates (Agilent) at density of $50 \times 10^{3}$ cells/ well. $24 \mathrm{~h}$ after seeding, growth medium was replaced with Seahorse XF DMEM medium (Agilent) supplemented with $10 \mathrm{mM}$ glucose, $1 \mathrm{mM}$ pyruvate and $2 \mathrm{mM}$ glutamine. Cells were incubated for $1 \mathrm{~h}$ at $37{ }^{\circ} \mathrm{C}$ in normal atmosphere (no additional $\mathrm{CO}_{2}$ ) and then transferred into Seahorse. In Seahorse, cells were treated with ouabain or vehicle for $\sim 3 \frac{1}{2}$ $\mathrm{h}$, which was followed by successive treatment with $1 \mu \mathrm{M}$ oligomycin, $0.75 \mu \mathrm{M}$ FCCP, and a combination of $1 \mu \mathrm{M}$ rotenone and $1 \mu \mathrm{M}$ antimycin $\mathrm{A}$.

\section{Analysis of Cell Death with Flow Cytometry}

At the end of the experiment cells were detached with trypsinization and stained with FITC-conjugated annexin V (for detection of phosphatidylserine on the outer membrane of 
apoptotic cells) and propidium iodide (PI; for detection of cells with permeable cell membrane) using Annexin V FITC Assay Kit (No. 600300, Cayman Chemical). Cells were analysed with Cell Lab Quanta SC flow cytometer (Beckman Coulter) and divided into four populations based on the intensity of FITC and PI fluorescence: live (low FITC, low PI), early apoptotic (high FITC, low PI), late apoptotic (high FITC, high PI), and necrotic (low FITC, high PI).

\section{2-Deoxy-Glucose (2-DG) Uptake Assay}

Glucose uptake was determined by measuring the uptake of tritium $\left({ }^{3} \mathrm{H}\right)$-labelled 2-deoxy-glucose (2-DG), as described (Dolinar et al. 2018; Pirkmajer et al. 2015). Cells were washed with HEPES-buffered saline (HBS: $140 \mathrm{mM} \mathrm{NaCl}$, $20 \mathrm{mM}$ HEPES, $5 \mathrm{mM} \mathrm{KCl}, 2.5 \mathrm{mM} \mathrm{MgCl}_{2}, 1 \mathrm{mM} \mathrm{CaCl}_{2}$, $\mathrm{pH}$ 7.4) and incubated in HBS with $10 \mu \mathrm{M} 2-\mathrm{DG}$ and $1 \mu \mathrm{Ci} /$ $\mathrm{mL} 2-\left[1,2-{ }^{3} \mathrm{H}\right]-\mathrm{DG}$ (PerkinElmer) for $10 \mathrm{~min}$ at $37{ }^{\circ} \mathrm{C}$. Cells were subsequently washed with PBS supplemented with $25 \mathrm{mM}$ glucose and lysed with $0.04 \%$ (wt/vol) SDS in water. Cell lysates were then analysed for protein content with Pierce BCA Protein Assay Kit (Thermo Fisher Scientific) or mixed with liquid scintillation cocktail Aquasol 2 (PerkinElmer) and analysed for radioactivity with MicroBeta TriLux scintillation counter (PerkinElmer). Amount of 2-DG taken up by the cells was determined with the help of a standard (HBS with $10 \mu \mathrm{M}$ 2-DG and $1 \mu \mathrm{Ci} / \mathrm{mL} 2$ 2-[1,2$\left.\left.{ }^{3} \mathrm{H}\right]-\mathrm{DG}\right)$ and expressed in $\mathrm{pmol} / \mathrm{min} / \mathrm{mg}$ of protein. Control cells were treated with inhibitors of glucose transporters (phlorizin $(100 \mu \mathrm{M})$ or cytochalasin $\mathrm{B}(10 \mu \mathrm{M}))$ during 2-DG uptake to confirm that 2-DG was taken up via glucose transporters.

\section{Lactate Dehydrogenase (LDH), Lactate, Protein and DNA Assays}

Lactate dehydrogenase (LDH) and lactate in cell medium were measured with Cytotoxicity Detection Kit (LDH) (Roche) and Lactate Assay Kit (Merck), respectively. The total protein content was determined with Pierce BCA Protein Assay Kit (Thermo Fisher Scientific). All assays were performed according to the manufacturer's instructions. The DNA content was determined with a DNA assay based on the fluorescent DNA dye Hoechst 33342 (Thermo Fisher Scientific) as described (Rajh et al. 2016). Briefly, after lysis with $0.04 \%$ (wt/vol) SDS in water cell lysates were transferred to a 96 -well microplate, diluted to $100 \mu \mathrm{L}$ with water and mixed with $100 \mu \mathrm{L}$ of Tris- $\mathrm{NaCl}$ buffer $(50 \mathrm{mM}$ Tris, $100 \mathrm{mM} \mathrm{NaCl}$, pH 8.3) with $10 \mu \mathrm{g} / \mathrm{mL}$ Hoechst 33342. Samples were incubated for $15 \mathrm{~min}$ at room temperature and then Hoechst fluorescence was measured with VICTOR microplate reader (PerkinElmer) using $355 \mathrm{~nm}$ excitation filter and $460 \mathrm{~nm}$ emission filter.

\section{ADP/ATP Ratio Assay}

The ADP/ATP ratio was determined with ADP/ATP Ratio Assay Kit (Merck) according to the manufacturer's instructions. Cells were seeded in white 96-well microplates with clear bottom (PerkinElmer). Luminescence was measured with VICTOR microplate reader.

\section{Statistical Analysis}

Results are presented as means with standard error of the mean $( \pm$ SEM). Results were statistically analysed with GraphPad Prism 6 software using one-way ANOVA followed by Bonferroni's or Dunnett's post hoc test to compare different treatments and control samples or Student's t-test to compare only two samples. $P \leq 0.05$ was considered as statistically significant.

\section{Results}

\section{A Validation of the Primary Antibodies Against NKAa1 and Phospho-NKAa1 (Tyr10)}

NKA $\alpha 1$ is the predominant NKA $\alpha$ isoform in HK- 2 cells; however, they also express NKA $\alpha 3$ (Fig. 2A), with which the antibodies against the NKA $\alpha 1$ isoform might crossreact. To test this possibility, NKA $\alpha 1$ (Fig. 2B) or NKA $\alpha 3$ (Fig. 2C) were knocked-down by siRNA. Gene silencing of NKA $\alpha 1$ markedly reduced the intensity of the immunoreactive band at the $\sim 102 \mathrm{kDa}$ molecular weight marker, which was detected with two different (Ab1 and Ab2) antiNKA $\alpha 1$ primary antibodies (Fig. 2D,E,H). The phosphorylation of Tyr 10 of NKA $\alpha 1$ was also detected with two (mAb and $\mathrm{pAb}$ ) different primary antibodies (Fig. 2F-H). In addition to the $\sim 102 \mathrm{kDa}$ band, which was sensitive to gene silencing of NKA $\alpha 1$, these antibodies detected another band at the $\sim 76 \mathrm{kDa}$ molecular weight marker (Fig. 2F-H), whose intensity was the same in control and NKA $\alpha 1$-deficient cells. Gene silencing of NKA $\alpha 3$ had no effect on the detection of the total NKA $\alpha 1$ or the phosphorylated NKA $\alpha 1$ (Tyr10) (Fig. 2I-K).

Taken together with extremely low expression of NKA $\alpha 2$ mRNA (Fig. 2A), these results suggested that these primary antibodies were suitable for detection of the total or phosphorylated NKA $\alpha 1$ in HK-2 cells. All further analyses were carried out with the monoclonal antibody (Ab1) against the total NKA $\alpha 1$ and the monoclonal antibody (mAb) against the phosphorylated NKA $\alpha 1$ (Tyr10). The details about the antibodies are presented in Table 1. 


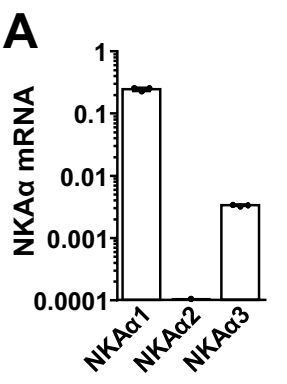

B
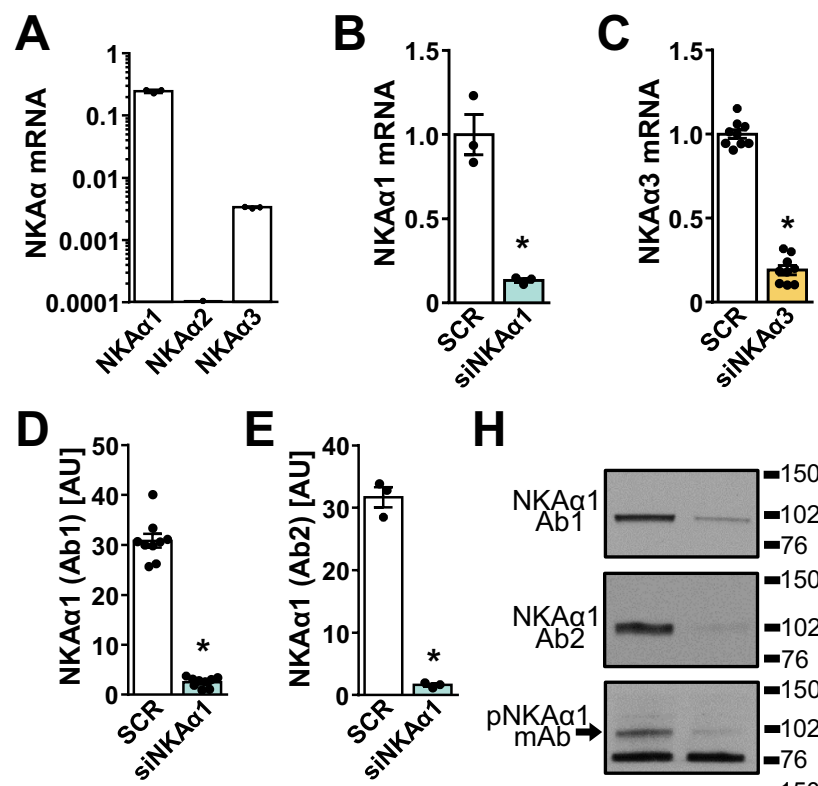

H

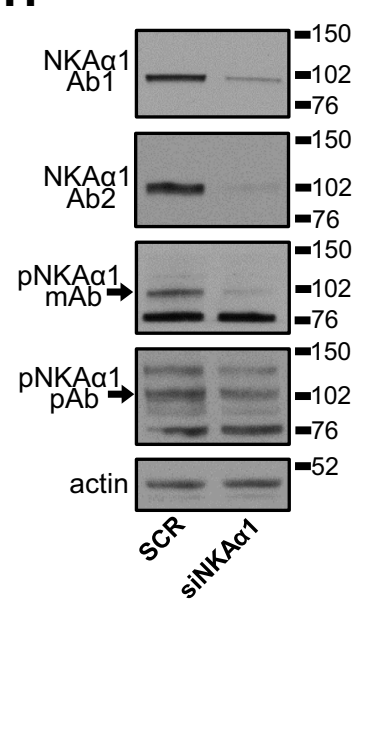

I

$\mathbf{F}$
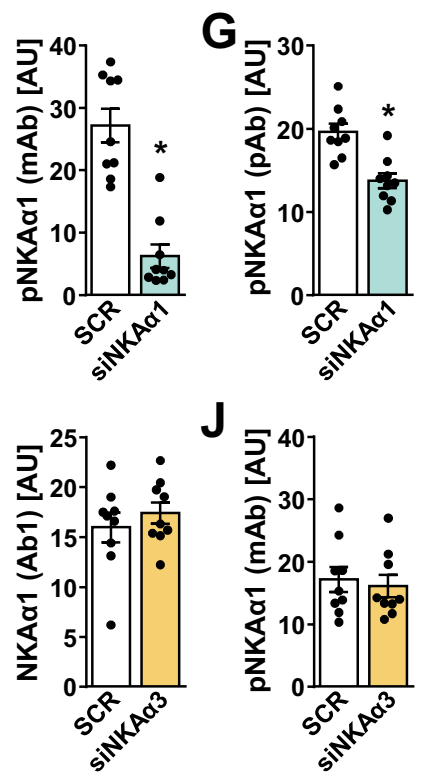

K

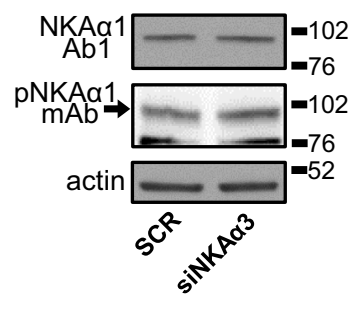

Fig. 2 Validation of primary antibodies against NKA $\alpha 1$ and phospho-NKA $\alpha 1$ (Tyr10). A The mRNA expression of NKA $\alpha$ isoforms in HK-2 cells reported as gene expression ratio. The endogenous control was cyclophilin A (PPIA). Results are means with SEM, $n=3$ (one experiment). B-K Gene silencing of NKA $\alpha 1(\mathbf{B}, \mathbf{D}-\mathbf{H})$ or NKA $\alpha 3(\mathbf{C}, \mathbf{I}-\mathbf{K})$ in HK-2 cells was performed to evaluate the specificity of primary antibodies against NKA $\alpha 1$ and phospho-NKA $\alpha 1$ (Tyr10) (pNKA $\alpha 1)$. Gene expression and protein abundance were measured $48 \mathrm{~h}$ after exposure to $5 \mathrm{nM}$ scrambled siRNA (SCR) or siRNA against NKA $\alpha 1$ ( $\operatorname{siNKA} \alpha 1)$ or NKA $\alpha 3$ (siNKA $\alpha 3)$. qPCR was performed to estimate NKA $\alpha 1$ (B) and NKA $\alpha 3$ (C) mRNA expression. Results are reported as foldchange relative to the SCR-treated cells. The endogenous control was cyclophilin A (PPIA), $n=3$ or 9 (one or three experiments). Immunoblotting was used to estimate the abundance of the total NKA $\alpha 1(\mathbf{D}, \mathbf{E}, \mathbf{I})$ and phospho-NKA $\alpha 1$ (Tyr10) (F, G, J) using four different antibodies: mAb \#05-369 (Ab1) (D, I) or $\mathrm{mAb} \# 23566$ (Ab2) for NKA $\alpha 1$ (E) and mAb \#13566 (F, J) or pAb \#3060 (G) for pNKA $\alpha 1$ (Tyr10). Representative blots of silencing of NKA $\alpha 1$ are shown in panel $\mathbf{H}$ and of NKA $\alpha 3$ in panel $\mathbf{K}$. Numbers next to the blots indicate molecular weight markers (kDa). Results of immunoblotting are presented as means with SEM, three independent experiments, $n=9$, except in panel $\mathbf{E}$ (one experiment, $n=3)$. ${ }^{*} P<0.05$ vs. SCR (Student's $t$-test)

\section{Effect of Insulin and EGF on the Phosphorylation of NKAa1 (Tyr10)}

HK-2 cells were treated with $10 \%$ FBS (30 min) or $120 \mathrm{nM}$ insulin (5-60 min) (Fig. 3). FBS increased the phosphorylation of NKA 1 (Tyr10) although its effect was variable (Fig. 3A), possibly due to the use of different batches. Insulin did not increase the phosphorylation of NKA $\alpha 1$ (Tyr10) significantly as assessed with Dunnett's post hoc test (Fig. 3A), although phosphorylation tended to be increased in the insulin-treated samples at all time points. The most pronounced increase was detected with the 15-min insulin treatment, which was significant with Student's $t$-test. Due to a modest response of Tyr10 to the stimulation with insulin, the signalling pathways downstream of the insulin receptor were also assessed. Insulin increased the phosphorylation of Akt (Ser473) at all time points (Fig. 3B) and the phosphorylation of ERK1/2 (Thr202/Tyr204) at $60 \mathrm{~min}$ (Fig. 3C), indicating HK-2 cells were responsive to the insulin treatment. The phosphorylation of EGFR (Tyr1173) was increased by insulin during the entire time course (Fig. 3D). These results indicated that while phosphorylation of Tyr 10 in HK-2 cells is responsive to exogenous stimuli, insulin was not a strong stimulus.

To further explore the signalling pathways that link the extracellular signals to the phosphorylation of NKA 1 (Tyr10), HK-2 cells were treated with $1 \mu \mathrm{g} / \mathrm{mL}$ EGF $(10 \mathrm{~min})$ in the presence of EGFR inhibitor gefitinib $(10 \mu \mathrm{M})$ or tyrosine kinase inhibitor genistein $(100 \mu \mathrm{M})$ (Akiyama et al. 1987; Ogawara et al. 1986) (Fig. 4K). EGF markedly increased the phosphorylation of NKA $\alpha 1$ at Tyr10 (Fig. 4A). The increase in Tyr10 phosphorylation was prevented by gefitinib and blunted by genistein (Fig. 4A). This was paralleled by a complete suppression of the EGF-stimulated phosphorylation of EGFR (Fig. 4B) and ERK1/2 (Fig. 4D) by gefitinib. Genistein increased the activating phosphorylation of Src (Tyr416) (Fig. 4C), but had no effect on the EGFR or ERK1/2 phosphorylation in the EGF-treated HK-2 cells. We also measured the phosphorylation of acetyl-CoA carboxylase (ACC) at Ser79 (Fig. 4E), an AMPK substrate and an indicator of AMPK activation (Carling et al. 1987; Davies et al. 1990), which was markedly increased by genistein. These results showed that the EGF-stimulated phosphorylation of Tyr10 is completely suppressed by the EGFR inhibition and blunted by a non-specific inhibition of tyrosine kinases.

Src was shown to increase tyrosine phosphorylation of NKA $\alpha$ under in vitro conditions (Al-Khalili et al. 2003). Since Src is downstream of EGFR, we examined whether Src is required for the EGF-stimulated phosphorylation of Tyr 10 . HK- 2 cells were treated with $1 \mu \mathrm{g} / \mathrm{mL}$ EGF for 5 or $10 \mathrm{~min}$ in the presence or absence of PP2, an inhibitor of Src family of protein kinases. EGF stimulated the phosphorylation of 
Fig. 3 Time-dependent effects of insulin on NKA $\alpha 1$ phosphorylation and on the associated signalling pathways in $\mathrm{HK}-2$ cells. A-D HK-2 cells were treated with $10 \%$ FBS for 30 min or with $120 \mathrm{nM}$ insulin for 5-60 min as indicated. Immunoblotting was used to estimate protein levels of phospho-NKA $\alpha 1$ (Tyr10) (A), phospho-Akt (Ser473) (B), phospho-ERK1/2 (Thr202/ Tyr204) (C), phospho-EGFR (Tyr1173) (D). Numbers next to the blots indicate molecular weight markers ( $\mathrm{kDa}), \mathbf{B}$ basal. Results are means with SEM (three independent experiments, $n=12) . * P<0.05$ vs. basal (unpaired one-way ANOVA, Dunnett's test), ${ }^{\#} P<0.05$ vs. basal (Student's $t$-test)
A

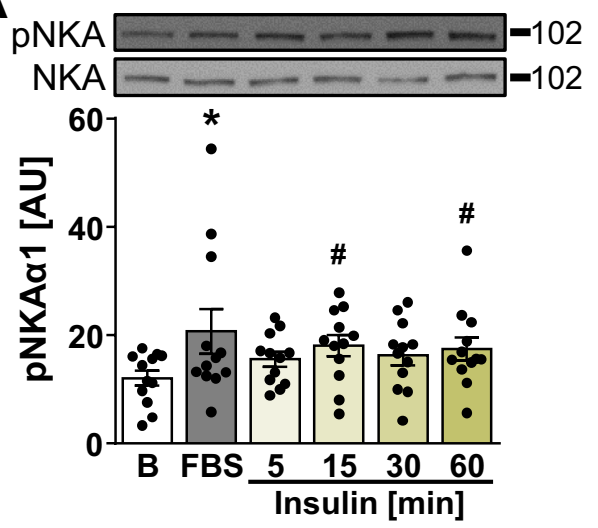

C

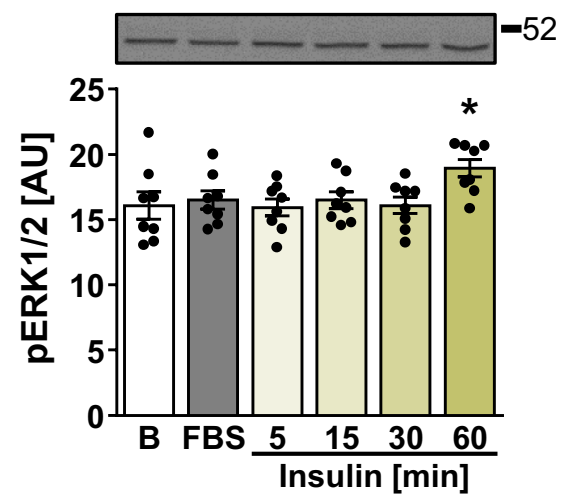

B

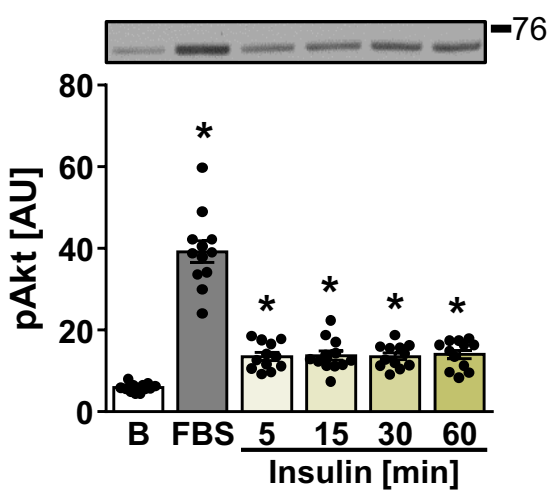

D

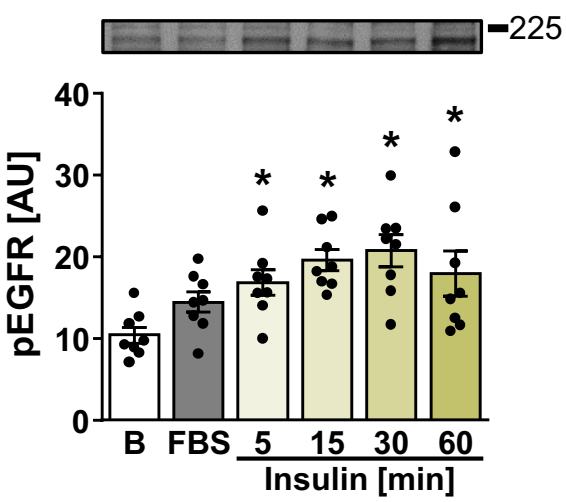

NKA $\alpha 1$ (Tyr10) (Fig. 4F), EGFR (Fig. 4G), Src (Fig. 4H), as well as ERK1/2 (Fig. 4I). PP2 markedly suppressed the phosphorylation of Src in the absence or presence of EGF (Fig. $4 \mathrm{H}$ ) and prevented the EGF-stimulated increase in NKA $\alpha 1$ (Tyr10) phosphorylation (Fig. 4F). PP2 blunted but did not prevent the EGF-stimulated phosphorylation of EGFR and ERK1/2 (Fig. 4G, I). The phosphorylation of ACC, a substrate of AMPK, was somewhat increased by EGF (Fig. 4J). Taken together, these results suggested that EGF stimulated the phosphorylation of NKA $\alpha 1$ (Tyr10) via the EGFR-Src pathway.

\section{AMPK Suppresses EGF-Stimulated Phosphorylation of NKAa 1 in HK-2 Cells}

Pharmacological inhibition of EGFR/HER2 was shown to activate AMPK in cancer cells (Spector et al. 2007), indirectly suggesting that EGFR and AMPK may exert functionally opposing effects on the Tyr10 phosphorylation. HK-2 cells were treated with AICAR (Corton et al. 1995; Sullivan et al. 1994) and A-769662 (Cool et al. 2006), which bind to AMPK and activate it directly, and mitochondrial uncoupler FCCP and inhibitor of ATP synthase oligomycin, which activate AMPK by suppressing the ATP synthesis (Hawley et al. 2010; Rohas et al. 2007). The phosphorylation of Tyr10 was markedly increased by EGF, while AMPK activators did not alter it (Fig. 5A). The activating phosphorylation of AMPK at Thr172 was slightly increased by AICAR and oligomycin (Fig. 5B), while the phosphorylation of ACC was markedly increased by AICAR, A-769662, and FCCP (Fig. 5C), indicating AMPK activation. FCCP increased the phosphorylation of EGFR (Fig. 5D) and ERK1/2 (Fig. 5F), while A-769662 increased the phosphorylation of Src (Fig. 5E) and ERK1/2 (Fig. 5F).

These results did not support the notion that AMPK might modulate the phosphorylation of Tyr10. However, under basal conditions the phosphorylation of EGFR was low (Figs. 4G and 5D), while gefitinib (Fig. 4A) and PP2 (Fig. 4F) tended to have only a marginal effect on basal phosphorylation of Tyr10, indirectly suggesting that the EGFR-Src pathway may not be an important regulator of Tyr10 under non-stimulated conditions. To examine this possibility HK-2 cells were treated with EGF after being pretreated with AMPK activators AICAR and A-769662 (Fig. 5G-L). The EGF-stimulated phosphorylation of Tyr10 was suppressed by AICAR and abolished by A-769662 (Fig. 5G). Although only AICAR increased the phosphorylation of AMPK (Fig. 4H), a marked increase in the ACC phosphorylation (Fig. 5I) suggested potent AMPK activation by AICAR and A-769662. AICAR and A-769662 both 
Fig. 4 EGF regulates Tyr10 phosphorylation of NKA $\alpha 1$ in HK-2 cells via the EGFRSrc pathway. A-E HK-2 cells were pretreated with or without $10 \mu \mathrm{M}$ EGFR inhibitor gefitinib or $100 \mu \mathrm{M}$ tyrosine kinase inhibitor genistein for $60 \mathrm{~min}$ and stimulated with $1 \mu \mathrm{g} / \mathrm{mL}$ EGF during the last $10 \mathrm{~min}$ (two independent experiments, $n=8)$. $\mathbf{F}-\mathbf{J}$ HK-2 cells were pretreated with or without $20 \mu \mathrm{M}$ Src family kinase inhibitor PP2 for $25 \mathrm{~min}$ and stimulated with $1 \mu \mathrm{g} / \mathrm{mL}$ EGF during the final 5 or 10 min. Results are means with SEM (three independent experiments, $n=10$ ). Immunoblotting was used to estimate the abundance of phospho-NKA $\alpha 1$ (Tyr10) (A, F), phospho-EGFR (Tyr1173) (B, G), phospho-Src (Tyr416) (C, H), phosphoERK1/2 (Thr202/Tyr204) (D, I), and phospho-ACC (Ser79) $(\mathbf{E}, \mathbf{J})$. Numbers next to the blots indicate molecular weight markers (kDa). K Schematic presentation of signalling pathways and site of action of inhibitors used in this study. $S F K$ Src family kinases, $T K$ tyrosine kinases. $* P<0.05$ vs. basal, ${ }^{\#} P<0.05$ EGF/PP2 vs. no EGF/PP2 (unpaired one-way ANOVA, Bonferroni's test)
A

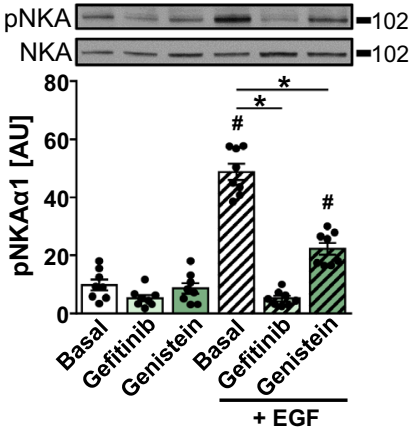

D

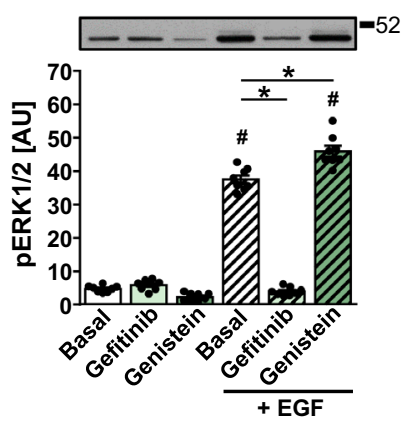

G

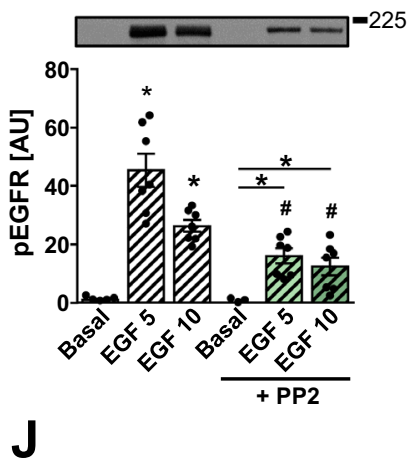

B

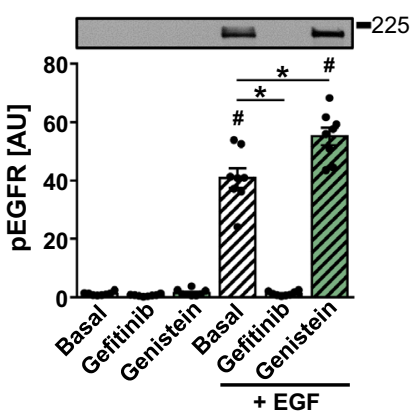

E
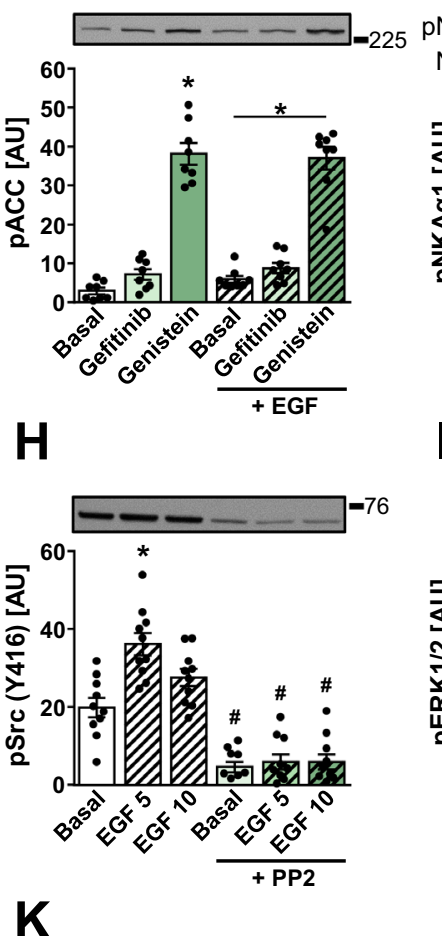

C

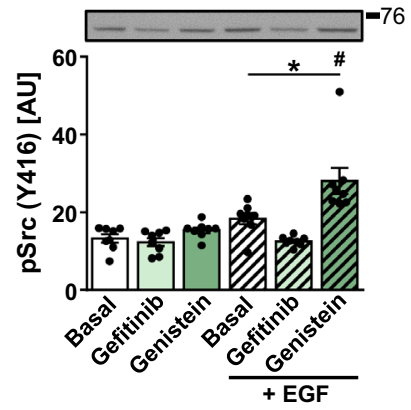

$\mathbf{F}$
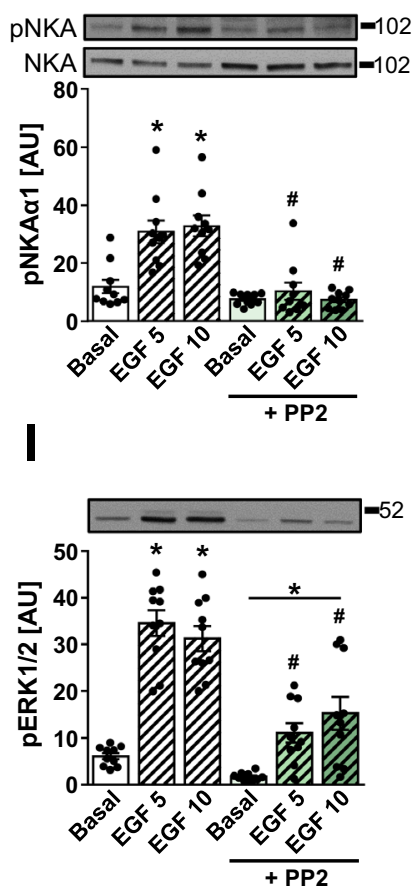

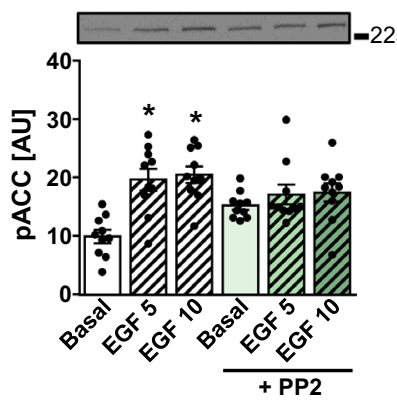

suppressed the EGF-stimulated EGFR phosphorylation (Fig. 5J), but they showed divergent effects on the phosphorylation of Src. Unlike AICAR, A-769662 potently increased the Src phosphorylation at Tyr416 with or without EGF (Fig. 5E, K). Similarly, while AICAR suppressed the phosphorylation of ERK1/2 in the absence of EGF, A-769662 stimulated it (Fig. 5L). Taken together, these results suggested that pharmacological AMPK activation opposed the EGF-stimulated phosphorylation of EGFR (Tyr1173) as well as NKA $\alpha 1$ (Tyr10), although AICAR and A-769662 produced divergent downstream signalling events. Further, they showed that activation of Src, as assessed by phosphorylation of Tyr416, per se was not sufficient to stimulate the phosphorylation of Tyr 10 . 
Fig. 5 AMPK suppresses EGFstimulated Tyr10 phosphorylation in HK-2 cells. A-F HK-2 cells were treated with direct and indirect AMPK activators for $60 \mathrm{~min}: 2 \mathrm{mM}$ AICAR, $300 \mu \mathrm{M}$ A-769662, $10 \mathrm{mM}$ 2-deoxy-glucose (2-DG, glycolysis inhibitor), $30 \mu \mathrm{M}$ FCCP (mitochondrial uncoupler) or $1 \mu \mathrm{M}$ oligomycin (inhibitor of ATP synthase). Stimulation with $1 \mu \mathrm{g} / \mathrm{mL}$ EGF for $10 \mathrm{~min}$ was used as a positive control of Tyr10 phosphorylation of NKA. G-L HK-2 cells were treated with $2 \mathrm{mM}$ AICAR or $300 \mu \mathrm{M}$ A-769662 for $60 \mathrm{~min}$. During the last $10 \mathrm{~min}$ HK-2 cells were stimulated with $1 \mu \mathrm{g} /$ $\mathrm{mL}$ EGF. Immunoblotting was used to estimate protein levels of phospho-NKA $\alpha 1$ (Tyr10)

(A, G), phospho-AMPK

(Thr172) (B, H), phospho-ACC (Ser79) (C, I), phospho-EGFR (Tyr1173) (D, J), phospho-Src (Tyr416) (E, K) and phosphoERK1/2 (Thr202/Tyr204) (F,

L). Numbers next to the blots indicate molecular weight markers $(\mathrm{kDa})$. Results are means with SEM (two independent experiments, $n=8)$. $\mathbf{A}-\mathbf{F}$ $* P<0.05$ vs. basal (unpaired one-way ANOVA, Dunnett's test). G-L $* P<0.05$ vs. basal, ${ }^{\#} P<0.05$ EGF vs. no EGF (unpaired one-way ANOVA, Bonferroni's test)
A

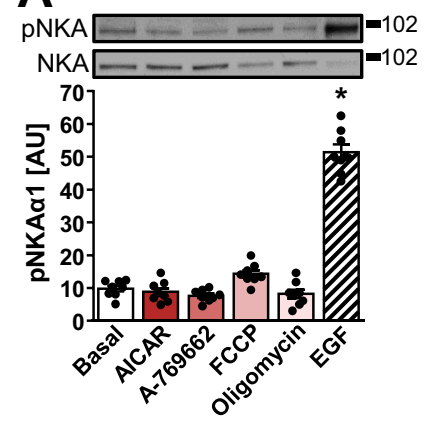

D

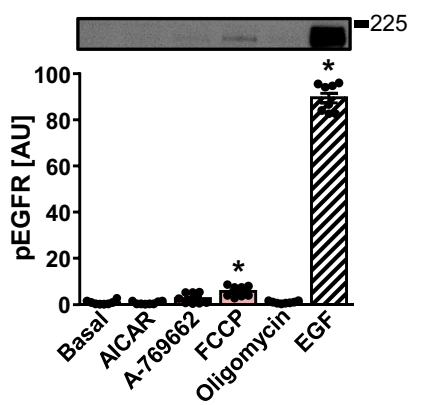

G
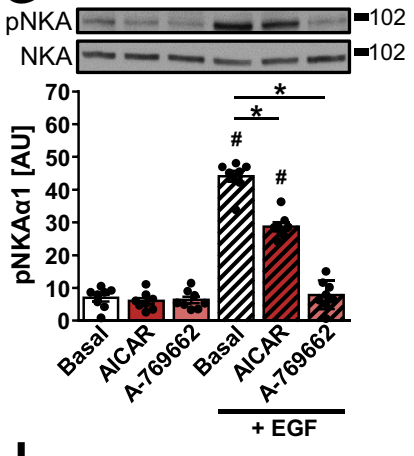

J

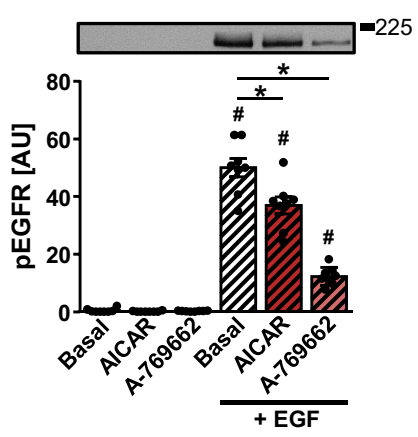

B

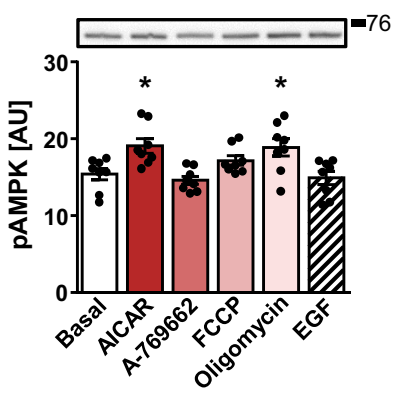

E

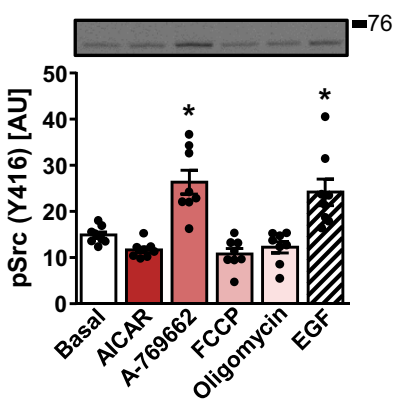

H

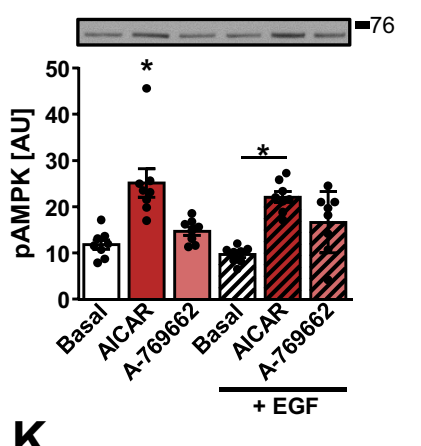

K

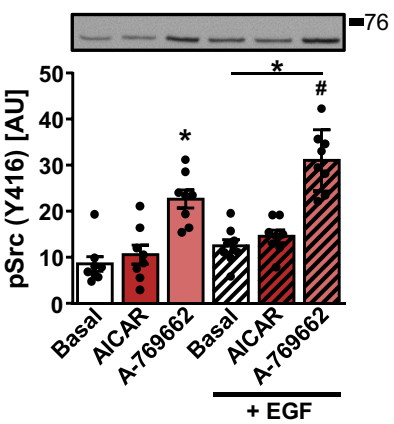

C

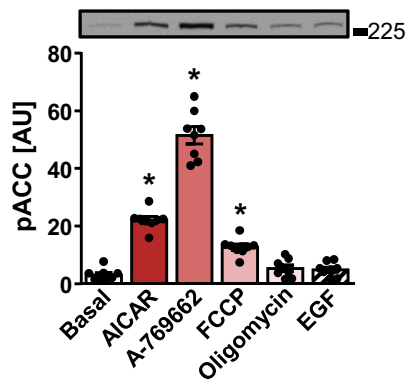

$\mathbf{F}$

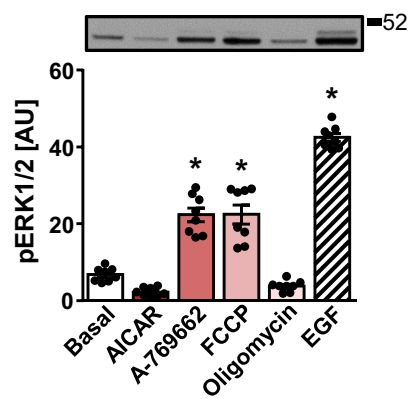

I
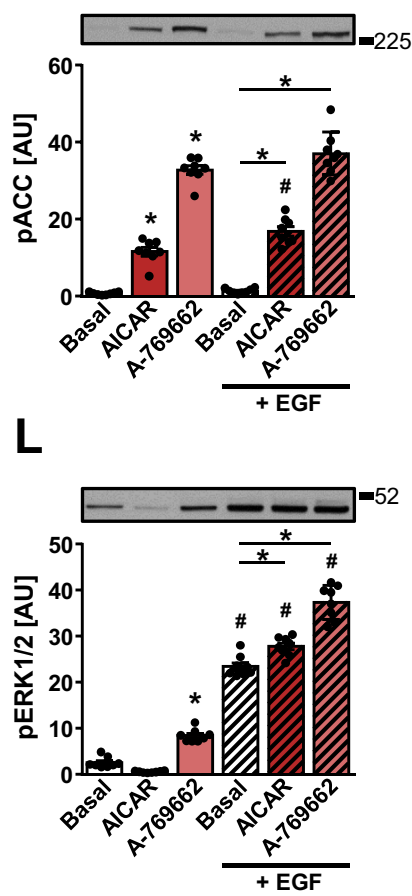

\section{Ouabain Enhances the EGF-Stimulated Phosphorylation of NKAa1 (Tyr10) in HK-2 Cells}

To explore the possibility that ouabain affects the phosphorylation of Tyr10 via Src, HK-2 cells were treated with $100 \mathrm{nM}$ ouabain. The treatment with ouabain (5-60 min) did not alter the phosphorylation of NKA $\alpha 1$ at Tyr10
(Fig. 6A), EGFR (Fig. 6B), and Src (Tyr416) (Fig. 6C). The inhibitory phosphorylation of Src at Tyr527 was increased at $60 \mathrm{~min}$ (Fig. 6D), while the phosphorylation of ERK1/2 was suppressed between 15-60 min of the ouabain treatment (Fig. 6E). The phosphorylation of ACC was unaltered (Fig. 6F). 
Fig. 6 Ouabain enhances EGFstimulated Tyr10 phosphorylation in HK-2 cells. A-F HK-2 cells were treated with $100 \mathrm{nM}$ ouabain for $5,10,15,30$ or 60 min. G-L HK-2 cells were treated with $300 \mu \mathrm{M}$ A-769662 or $100 \mathrm{nM}$ ouabain for $60 \mathrm{~min}$. $1 \mu \mathrm{g} / \mathrm{mL}$ EGF was added during the last $10 \mathrm{~min}$. Immunoblotting was used to estimate the abundance of phospho-NKA $\alpha 1$ (Tyr10) (A, G), phospho-EGFR (Tyr1173) (B, H), phospho-Src (Tyr416) (C, I), phospho-Src (Tyr527) (D), phospho-ERK1/2 (Thr202/Tyr204) (E, J), phospho-ACC (Ser79) (F, L), and phospho-AMPK (Thr172) (K). Numbers next to the blots indicate molecular weight markers (kDa), B basal. Results are means with SEM (two or three independent experiments, $n=8-12)$. A-F $* P<0.05$ vs. basal (unpaired one-way ANOVA, Dunnett's test). G-L ${ }^{*} P<0.05$ vs. basal, ${ }^{\#} P<0.05$ EGF vs. no EGF (unpaired oneway ANOVA, Bonferroni's test)
A

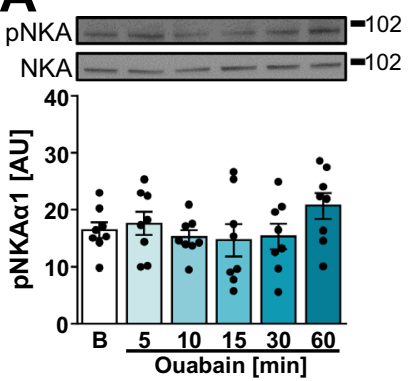

B
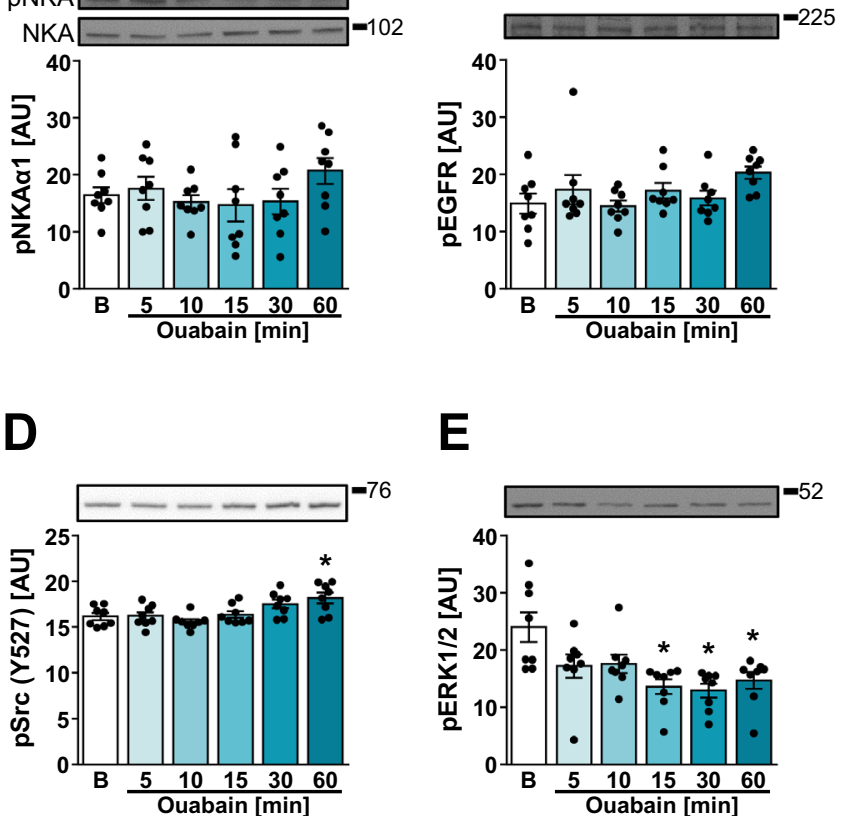

G
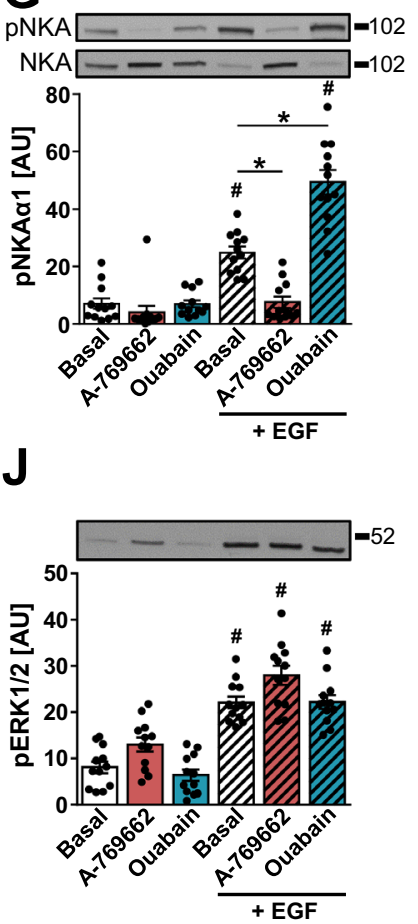

E

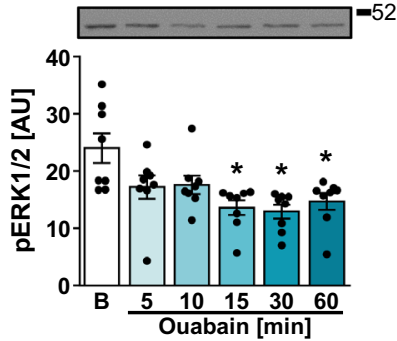

H
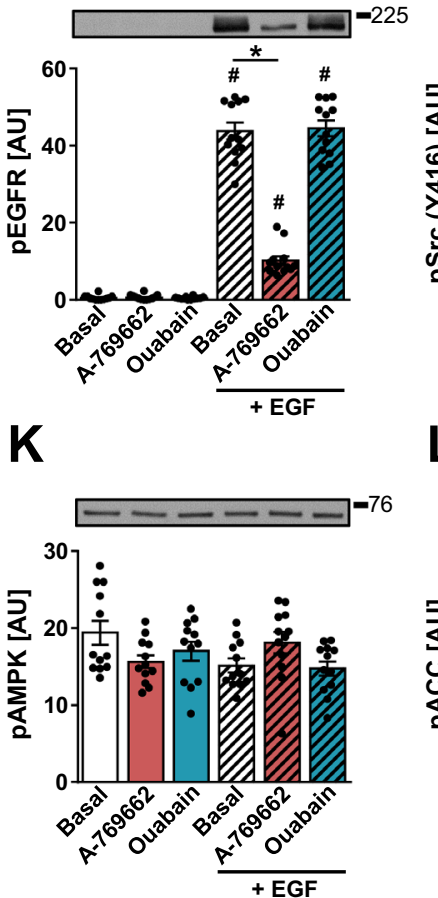

HK- 2 cells were then treated with $1 \mu \mathrm{g} / \mathrm{mL}$ EGF (10 min) in the absence or presence of $100 \mathrm{nM}$ ouabain or $300 \mu \mathrm{M}$ A-769662 (Fig. 6G-L). Ouabain enhanced the EGF-stimulated phosphorylation of NKA $\alpha 1$ (Tyr10) (Fig. 6G), while it did not affect the phosphorylation of EGFR (Fig. $6 \mathrm{H}$ ) or Src (Tyr416) (Fig. 6I). AMPK activator A-769662 again suppressed the EGF-stimulated phosphorylation of Tyr10
$\mathbf{F}$
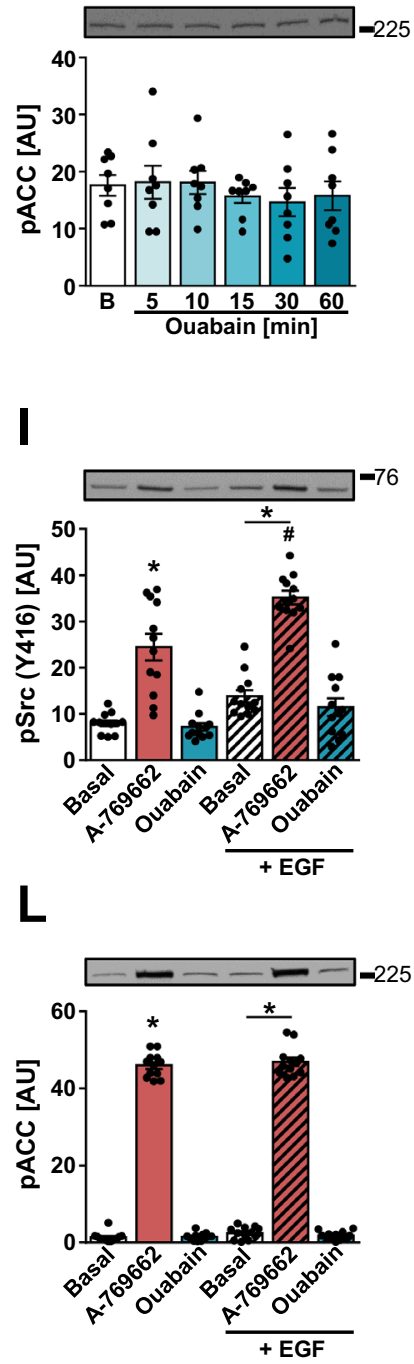

C
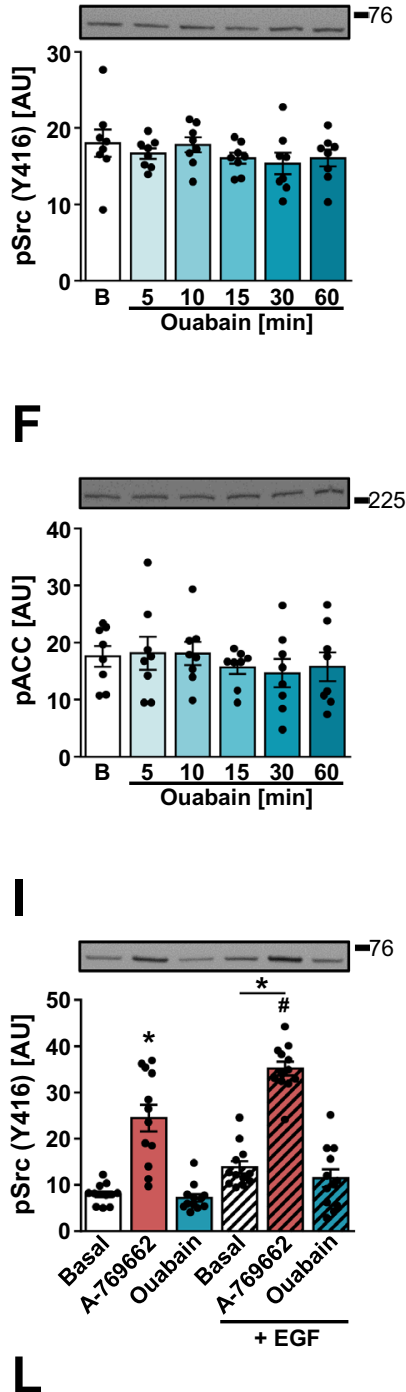

(Fig. 6G) and EGFR (Fig. 6H), while enhancing the EGFstimulated phosphorylation of Src (Tyr416) (Fig. 6I). The phosphorylation of ERK1/2 was unaltered by ouabain, while it was increased by A-769662 (Fig. 6J). Ouabain did not modulate the phosphorylation of ERK1/2, AMPK, and/ or ACC (Fig. 6J-L). Taken together, these results showed that ouabain markedly enhanced the EGF-stimulated 
phosphorylation of Tyr10 without enhancing the phosphorylation of EGFR (Tyr1173) or Src (Tyr416).

\section{The Role of NKAa1 and NKAa3 in Regulation of Intracellular Signalling in HK-2 Cells Under Basal Conditions}

Ouabain had only a minor effect on intracellular signalling pathways under basal conditions (Fig. 6). To further explore the link between NKA and signalling in HK-2 cells, we measured the abundance of multiple phosphoproteins involved in signalling via EGFR and insulin receptor after knocking-down NKA $\alpha 1$ or NKA $\alpha 3$ with siRNA (Fig. 7). The knock-down of NKA $\alpha 1$ suppressed the level of the phosphorylated Src (Tyr416) (Fig. 7B), while the total Src (Fig. 7A) and the phosphorylation at Tyr527 (Fig. 7C) were unaltered. Conversely, the knock-down of NKA $\alpha 3$ increased the total Src (Fig. 7A) and ERK1/2 (Fig. 7F), but did not alter their phosphorylation (Fig. 7B, C, G). The abundance of the total or phosphorylated EGFR (Fig. 7D, E), ACC (Fig. 7H,I), and Akt (Fig. 7J) was not altered by knockingdown NKA $\alpha 1$ or NKA $\alpha 3$.

\section{Effect of Ouabain on Cell Viability and Energy Metabolism}

Ouabain was used in concentrations that are sufficient to suppress pumping activity of human NKA $\alpha 1$ (Wang et al. 2001), which might have caused disruption of ion homeostasis, reduction of cell viability and/or metabolic alterations. On the other hand, inhibition of NKA by ouabain might have led to ATP savings and improved energy status, which would tend to oppose AMPK activation. To assess these possibilities, HK-2 cells were treated with $10-1000 \mathrm{nM}$ ouabain for $4 \mathrm{~h}$ (Fig. 8). Ouabain in high concentrations (300-1000 nM) somewhat reduced the content of DNA (Fig. 8A) and proteins (Fig. 8B), but did not increase release of lactate dehydrogenase (LDH) (Fig. 8C). As assessed by immunoblotting, caspase-3 was not activated by ouabain (Fig. 8D, E), indicating apoptosis was not induced. As estimated by flow cytometry, ouabain also did not increase the fraction of necrotic and apoptotic cells (Fig. 8F). These results demonstrated that $100 \mathrm{nM}$ ouabain did not cause significant cell death.

Ouabain reduced the lactate production in dose-dependent manner (Fig. 8G), which indirectly suggested that the rate of glycolysis was reduced due to NKA inhibition and
Fig. 7 The effects of silencing of NKA $\alpha 1$ and NKA $\alpha 3$ on NKA-associated signalling pathways in HK-2 cells. The effect of silencing of $\alpha 1$ (left parts of graphs) and $\alpha 3$-subunit (right parts of graphs) of NKA on phospho and total protein levels of Src, EGFR, Erk1/2, ACC, and Akt. The cells were treated with $5 \mathrm{nM}$ scrambled siRNA (SCR) or siRNA against NKA $\alpha 1$ or NKA $\alpha 3$ and cultured for $48 \mathrm{~h}$. For the last $8 \mathrm{~h}$ the cells were grown in DMEM w/o serum. Immunoblot was used to evaluate the effects of silencing on protein levels of Src (A), phospho-Src (Tyr416) (B), phospho-Src (Tyr527) (C), EGFR (D), phospho-EGFR (Tyr1173) (E), ERK1/2 (F), phospho-ERK1/2 (Thr202/ Tyr204) (G), ACC (H), phospho-ACC (Ser79) (I) and phospho-Akt (Ser473) (J). Numbers next to the blots indicate molecular weight markers $(\mathrm{kDa})$. Results are mean with SEM (two or three independent experiments, $n=6-9)$ ). $* P<0.05$ vs. SCR (Student's $t$-test)
A

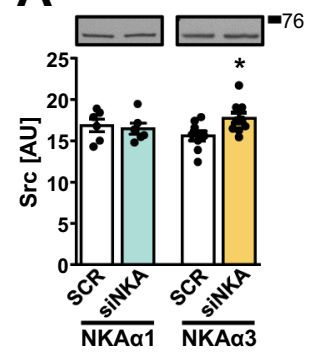

B
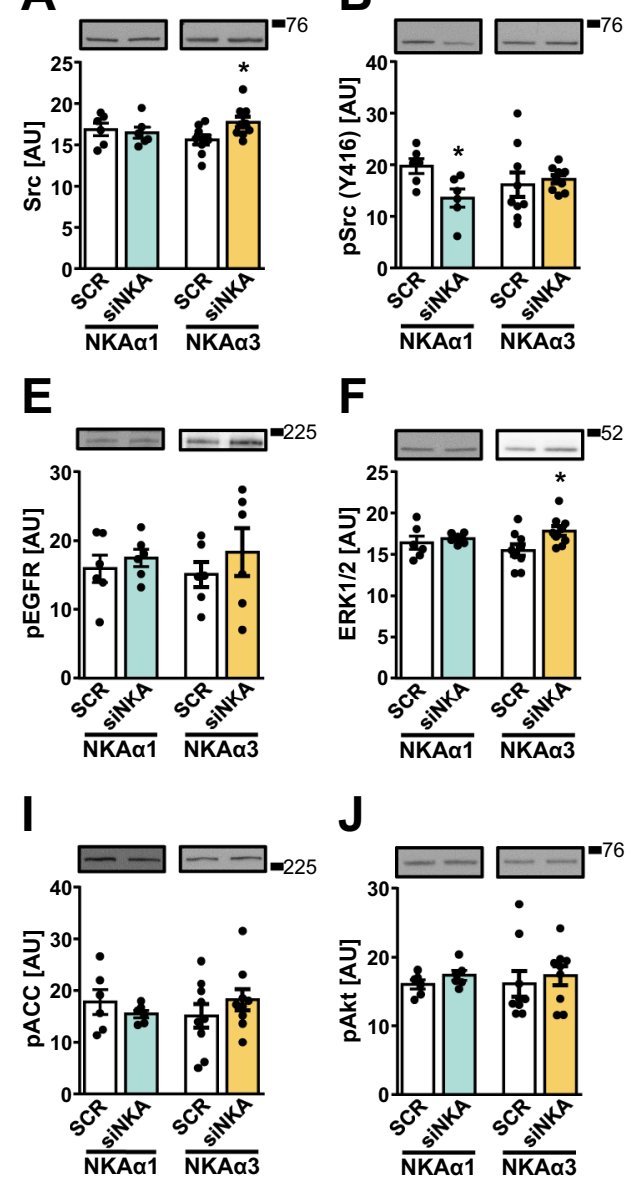

J

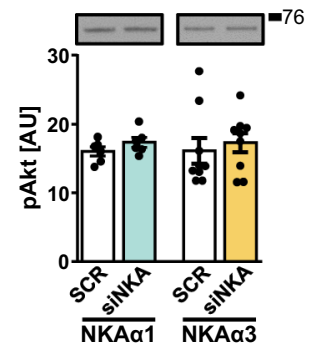

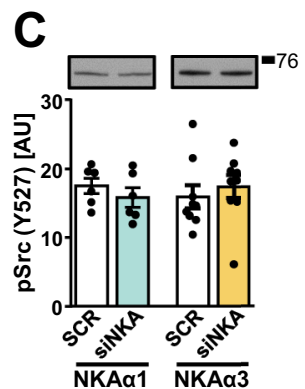

G
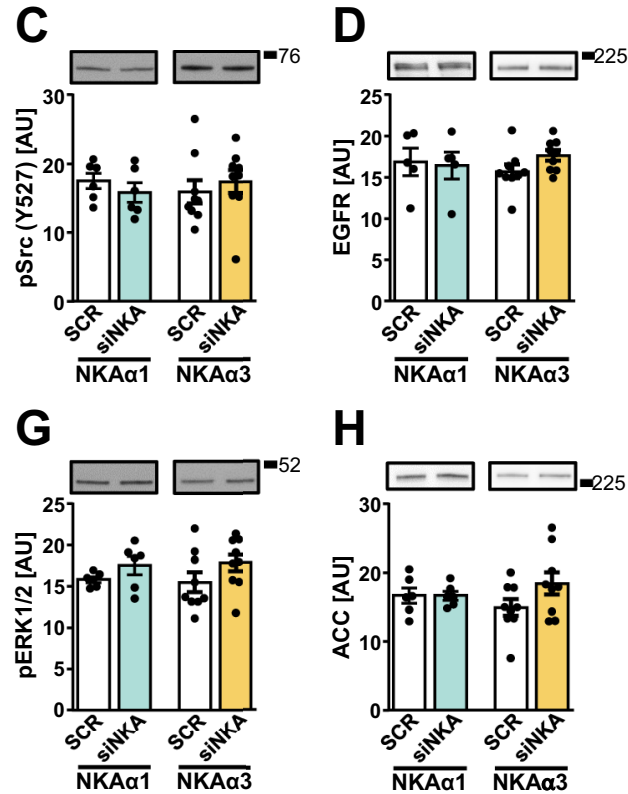

H

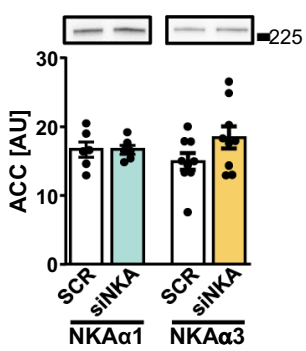


A
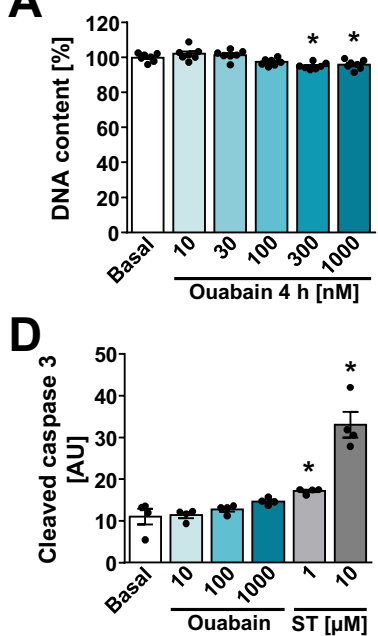

G

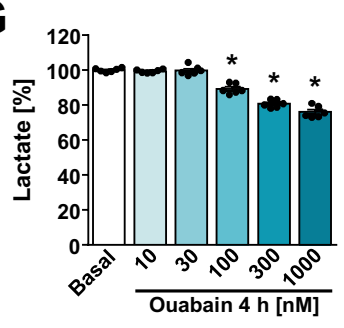

B

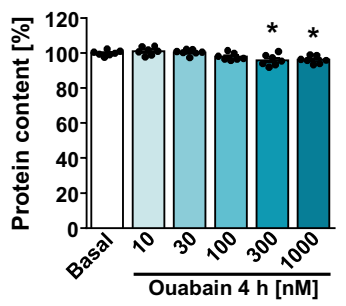

C

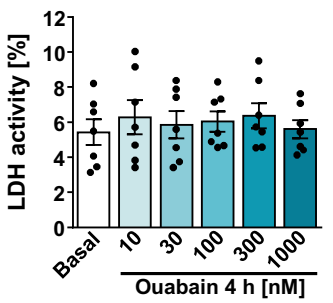

E

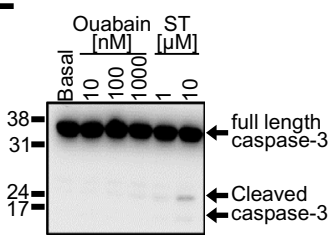

$\mathbf{F}$

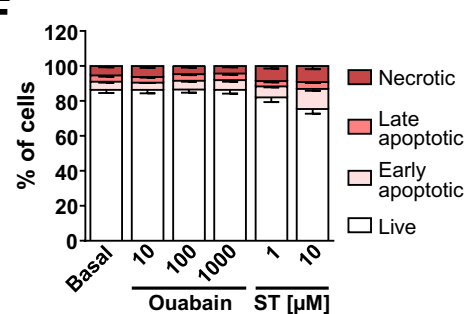

H

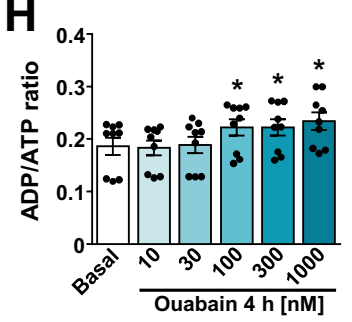

I

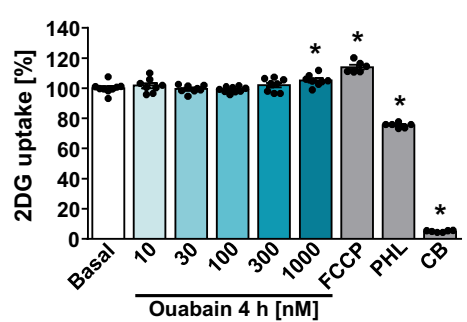

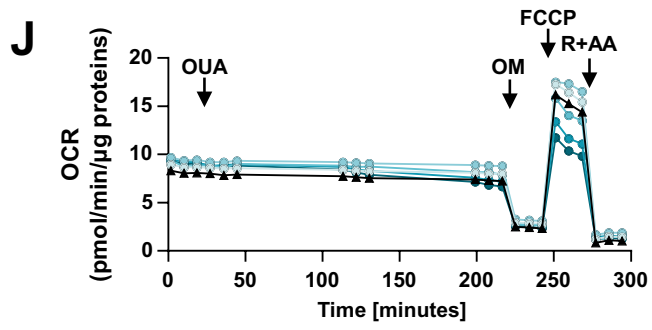

FCCP

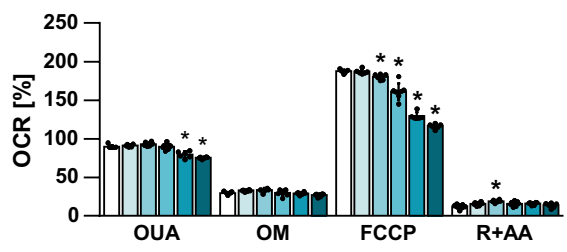

$\mathbf{K}$
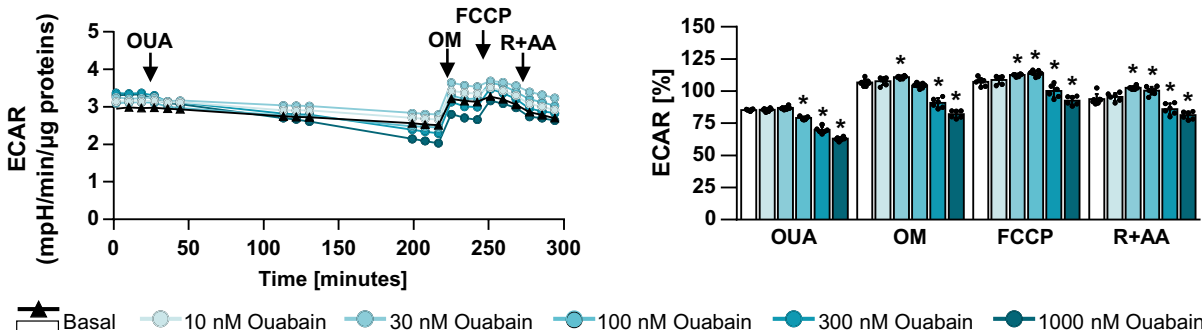

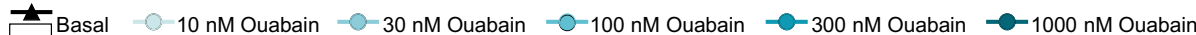

Fig. 8 Metabolic effects of ouabain in HK-2 cells. A-I HK-2 cells were incubated in serum-free DMEM and treated with indicated concentrations of ouabain (OUA, $4 \mathrm{~h}$ ), staurosporine (ST), phlorizin (PHL), or cytochalasin B (CB). DNA content (A), protein content $(\mathbf{B})$, LDH activity $(\mathbf{C})$, lactate production $(\mathbf{G})$, and the ADP/ATP ratio $(\mathbf{H})$ were measured using specific assays (see Methods). Immunoblotting (D, E) was used to estimate protein levels of full-length and cleaved caspase-3. Flow cytometry (F) was used to determine $\%$ of live, early apoptotic, late apoptotic, and necrotic cells. Glucose uptake (I) was evaluated by measuring the uptake of ${ }^{3} \mathrm{H}$-labelled 2-DG. DNA content, protein content, lactate production, and 2-DG uptake are expressed as \% of basal. LDH activity is expressed as \% of Triton X-100 treated group. J-K Oxygen consumption rate (OCR)
(J) and extracellular acidification rate (ECAR) (K) were analysed with Seahorse XFe24 Analyzer. Cells were treated with ouabain or vehicle for $3 \frac{1}{2} \mathrm{~h}$ before the sequential addition of oligomycin (OM), $\mathrm{FCCP}$, and a combination of rotenone and antimycin A ( $+\mathrm{AA})$. The graphs on the left show the average absolute changes in OCR and ECAR during the course of experiment according to the treatment scheme. The graphs on the right show OCR and ECAR (average of three measurements) after $3 \frac{11}{2} \mathrm{~h}$ of ouabain treatment and after addition of OM, FCCP, and R+AA, expressed as \% of basal (average of first three measurements before addition of ouabain). Results are means with SEM (two or three independent experiments, $n=6-9$ ). $* P<0.05$ vs. basal (unpaired one-way ANOVA, Dunnett's test) 
lower ATP consumption. However, treatment with ouabain increased the ADP:ATP ratio (Fig. 8H), which indicated that ouabain impaired the energy balance in HK-2 cells. To test whether ouabain altered glucose uptake, HK-2 cells were treated with ouabain (10-1000 nM), FCCP (a mitochondrial uncoupler), phlorizin (an inhibitor of $\mathrm{Na}^{+}$-coupled glucose transporters SGLT1 and 2), and cytochalasin B (a glucose transporter inhibitor) (Fig. 8I). Excepting the highest concentration $(1000 \mathrm{nM})$ ouabain did not alter the uptake of 2-deoxy-glucose (2-DG). FCCP increased 2-DG uptake, while phlorizin had a modest suppressive effect, indicating SGLT transporters were active in these cells. Cytochalasin B almost completely suppressed the uptake of 2-DG.

To determine whether ouabain altered mitochondrial function, the oxygen consumption rate (OCR) (Fig. 8J) and extracellular acidification rate (ECAR) (Fig. 8K) were determined in HK-2 cells. Under basal conditions OCR was reduced by 300 and $1000 \mathrm{nM}$ ouabain, while ECAR was reduced already by $100 \mathrm{nM}$ ouabain, consistent with the reduced lactate production (Fig. 8G). While this indicated that glycolytic ATP production was more sensitive to ouabain than oxidative metabolism, $30-100 \mathrm{nM}$ ouabain was sufficient to suppress the FCCP-stimulated (i.e. maximal) OCR, suggesting that mitochondrial function was highly sensitive to ouabain action.

\section{Discussion}

A major finding of our study is that the EGF-stimulated phosphorylation of NKA 1 at Tyr10 was suppressed by two different AMPK activators and enhanced by the cardiotonic steroid ouabain. This finding highlights the phosphorylation of Tyr10 as a focal point of regulation by multiple signalling pathways. Moreover, it implicates a role for AMPK in regulation of tyrosine phosphorylation of NKA.

EGF was previously shown to increase tyrosine phosphorylation of NKA $\alpha 1$ in the proximal tubules (Feraille et al. 1997). Here we extend this pioneering result by showing that EGF stimulates the phosphorylation of Tyr10, which likely occurs as a consequence of the activation of the EGFR-Src pathway. First, inhibition of EGFR by gefitinib blocked the EGF-stimulated phosphorylation of Tyr10, demonstrating that activation of EGFR is absolutely required for this effect. Second, EGF could not increase phosphorylation of Tyr10 in the presence of Src kinase inhibitor PP2. Importantly, EGF increased the phosphorylation of EGFR despite PP2, indicating that activation of EGFR does not lead to Tyr10 phosphorylation if Src is inhibited. Src and Lyn, another member of the Src kinase family, were previously shown to phosphorylate NKA $\alpha$ at tyrosine residues under in vitro conditions (Al-Khalili et al. 2003; Bozulic et al. 2004a), while PP2 blocked the phosphorylation of Tyr10 in ocular ciliary epithelial cells (Shahidullah et al. 2014). Finally, unlike Src the activation of ERK1/2 did not seem to be functionally important for regulation of Tyr 10 phosphorylation in HK-2 cells. Indeed, the phosphorylation of ERK1/2 was increased by EGF even in the presence of PP2, while A-769662, which suppressed Tyr 10 phosphorylation activated ERK1/2. Taken together, all this points to a mechanism whereby EGF stimulates EGFR, which in turn phosphorylates and activates Src or another member of the Src family, thus leading to the phosphorylation of Tyr 10.

Activation of AMPK by AICAR as well as A-769662 suppressed the EGF-stimulated phosphorylation of Tyr10. The phosphorylation of EGFR was suppressed by both AMPK activators, supporting the notion that activation of EGFR is important for the phosphorylation of Tyr10 by EGF. Consistent with our results, suppression of EGFR by AMPK was observed in cultured cancer cells (Jhaveri et al. 2015). In contrast, A-769662 increased the (activating) phosphorylation of Src at Tyr416 in HK-2 cells in the presence and absence of EGF. Despite an apparent activation of Src, the EGF-stimulated phosphorylation of Tyr 10 was markedly suppressed by A-769662, which may seem to contradict a role for Src as Tyr10 kinase. However, on the other hand, A-769662 did not alter the Tyr10 phosphorylation in the absence of EGF despite a marked increase in the phosphorylation of Src. These results suggest that activation of Src without activation of EGFR does not lead to phosphorylation of Tyr10.

One explanation for the dissociation between phosphorylation of Src and Tyr10 could be that A-769662 activates a pool of Src that is not co-localized with EGFR and NKA. Indeed, localization of non-receptor tyrosine kinases, such as Src, in the vicinity of their targets is important for their substrate specificity (de Diesbach et al. 2008; Miller 2003). Another explanation could be that the activation of AMPK stimulates tyrosine phosphatases, which oppose phosphorylation of Tyr10 by Src. This explanation is not unlikely, since AMPK was previously shown to regulate the phosphorylation of Ser18 via serine/threonine phosphatase PP2A (Benziane et al. 2012). In summary, our data suggest that AMPK blocks the phosphorylation of Tyr10 by suppressing activity of EGFR, but additional mechanisms, such as involvement of phosphatases, cannot be excluded.

PP2, a selective Src inhibitor, also inhibits EGFR, albeit significantly less potently ( $\mathrm{IC}_{50}$ of $480 \mathrm{nM}$ for EGFR versus $5 \mathrm{nM}$ for Src) (Hanke et al. 1996). It can therefore be speculated that $20 \mu \mathrm{M}$ PP2 at least partially inhibited EGFR, which would be consistent with a lower phosphorylation of Tyr1 173 after the stimulation with EGF. On the other hand, Src is a downstream target of EGFR and, once activated by it, Src can in turn phosphorylate and activate EGFR in a positive feedback manner (Biscardi et al. 1999). Thus, inhibition of Src by PP2 could also indirectly reduce the EGF-induced 
activation (phosphorylation) of EGFR. Although both mechanisms may have been involved, PP2 did not prevent the EGF-induced phosphorylation of EGFR, while abrogating the EGF-induced Tyr10 phosphorylation of NKA $\alpha 1$. This result suggests that the phosphorylation of Tyr 10 requires an increase in the Src activity and cannot be achieved by activation of EGFR alone.

However, it also needs to be considered that alterations in the phosphorylation of Src are not always a reliable marker of its activity, so results of immunoblots in the presence of inhibitors of Src, which bind to it directly, should be interpreted cautiously. Even well-established inhibitors, such as PP2, do not always result in predictable changes in the phosphorylation of Src. Intuitively, one could expect that pharmacological inhibition of Src results in a reduced phosphorylation of the activation site Tyr416 (aka Tyr418) and an increased phosphorylation of the inhibitory site Tyr527 (aka Tyr529). In direct contrast, PP2 (in concentrations that abolish Src activity) may enhance the phosphorylation of Src at Tyr416, induced by exogenous stimuli, such as bombesin and angiotensin II (Wu et al. 2005). A similar mechanism might explain why genistein enhanced the EGF-stimulated phosphorylation of Src at Tyr416 in our experiments. Further, PP2 alone does not necessarily reduce the basal phosphorylation of Src at Tyr416 or even increases it (Wu et al. 2005). This means that the phosphorylation of Tyr416 is not a reliable marker of the Src activity in the presence of PP2. In addition, PP2 does not enhance the phosphorylation of Src at the inhibitory site Tyr527, but may even promote its dephosphorylation (Wu et al. 2005), which again highlights the challenge of assessing activity of kinases from their phosphorylation status in the presence of pharmacological inhibitors.

Clearly, pharmacological inhibition of Src does not result in simple alterations of its phosphorylation status, from which activity of Src could be inferred under all conditions. Similarly, high glucose concentrations or phorbol 12-myristate 13-acetate increased the phosphorylation of Ser and Thr residues and decreased the NKA activity, while insulin increased the phosphorylation of Ser, Thr, and Tyr residues and increased the NKA activity in rat skeletal muscle (Chibalin et al. 2001). Thus, an increase in Ser and Thr phosphorylation was associated both with an increase and a decrease of the NKA activity, which demonstrates that the final physiological effect is likely dependent on the phosphorylation pattern of all functionally important phosphosites and possibly also on the phosphorylation status of proteins that are involved in regulation of NKA trafficking and/or activity.

The physiological role of AMPK is frequently assessed by using pharmacological AMPK activators. The challenge of this approach is that pharmacological compounds have off-target effects that are not directly dependent on AMPK activation, which makes interpretation of results challenging. This complexity can be appreciated also in our results, which clearly showed that activation of AMPK by AICAR and A-769662 did not produce the same signalling responses. For instance, the phosphorylation of Src as well as ERK1/2 was markedly increased by A-769662. In contrast, AICAR did not alter the phosphorylation of Src, but it suppressed the phosphorylation of ERK1/2 under basal conditions (in the absence of EGF). Despite these differences both AMPK activators decreased the phosphorylation of EGFR as well as NKA $\alpha 1$ at Tyr10, which strengthens the argument that AMPK plays a role in regulation of Tyr10 phosphorylation via inhibition of the EGFR signalling.

Ouabain enhanced the EGF-stimulated phosphorylation of Tyr10 although it had no effect when used alone. Importantly, EGF action on Tyr10 was enhanced although phosphorylation of EGFR and Src were similar between the EGF and the combined (EGF and ouabain) treatment. While the underlying mechanism was not dissected it seems clear that ouabain did not promote the phosphorylation of Tyr10 by augmenting the activation of EGFR-Src pathway. We can therefore speculate that ouabain might have induced conformational changes in NKA $\alpha 1$ that made Tyr10 more accessible to phosphorylation by Src. Alternatively, ouabain might have enhanced the association between NKA and Src. If ouabain increased the interaction between NKA and Src via either of these two mechanisms, the pool of activated Src molecules may have been more efficient at phosphorylating Tyr10. This hypothesis is consistent with the above stated idea that A-769662 activated a pool of Src that was not close to NKA. Notably, ouabain increased interaction between Src and NKA $\alpha 1$ and NKA $\alpha 2$ in isolated skeletal muscle (Kotova et al. 2006b), which supports the idea that ouabain might increase phosphorylation of Tyr10 without affecting the activity of EGFR and other upstream signalling pathways.

The EGFR/Src/ERK1/2 signalling pathway was traditionally considered to be a particularly important link between ouabain and its intracellular effects. However, its universal significance as well as the underlying molecular mechanisms that link NKA to this pathway have recently been questioned (Askari 2019a, b). While the present study was not designed to test the importance of this pathway for ouabain actions, our results do seem to suggest that relatively short treatment with ouabain did not induce marked signalling responses in HK-2 cells. This observation is consistent with our recent study in cultured human skeletal muscle cells, in which we showed that most signalling responses occurred during prolonged ouabain treatments, which suggested that they had been mediated by alterations in intracellular concentrations of $\mathrm{Na}^{+}$and $\mathrm{K}^{+}$(Pirkmajer et al. 2020). Moreover, in HK-2 cells ouabain somewhat suppressed the phosphorylation of ERK1/2 and induced a minor increase in the inhibitory phosphorylation of Src (Tyr527), which again shows that ouabain 
did not acutely activate the EGFR/Src/ERK1/2 pathway in HK- 2 cells. Gene silencing of NKA $\alpha 1$ or NKA $\alpha 3$ also did not induce major changes in intracellular signalling in nonstimulated cells. Nevertheless, the abundance of the phosphorylated Src (Tyr416) in the NKA 1 1-deficient cells as well as the total Src and ERK1/2 in the NKA 33 -deficient cells was altered. Thus, although ouabain did not acutely activate the EGFR/Src/ERK1/2 pathway in HK-2 cells, our results are compatible with existence of a functional link between ouabain, NKA, and the EGFR/Src/ERK1/2 signalling.

Ouabain had no effect on the ATP production in isolated mitochondria (Kajikawa et al. 2002), but it can alter mitochondrial respiration via several indirect mechanisms. First, inhibition of NKA reduces the cellular demand for ATP, thus leading to reduced OCR, although this effect would depend on the cell type because fractional use of ATP by NKA varies widely between different cells and tissues (Clausen et al. 1991; Rolfe and Brown 1997). However, a reduction in ATP consumption did not seem to be a major mechanism in HK-2 cells because ouabain increased the ADP:ATP ratio, which indicated that the ATP production was impaired rather than reduced as a consequence of a lower demand for ATP. That ouabain impairs the ATP production was shown also in isolated pancreatic islets (Kajikawa et al. 2002) and cultured cancer cells (Shen et al. 2020). This impairment may result from inhibition of ion transport, which leads to osmotic imbalance, water uptake, and mitochondrial swelling (Leonard et al. 2015). On the other hand, while ouabain reduced the glucose oxidation in isolated skeletal muscle, inhibition of Src family kinases by PP2 blocked this effect (Kotova et al. 2006b), which not only shows that inhibition of ion transport per se is not always sufficient to alter mitochondrial function, but also highlights the link between ouabain-induced signalling via NKA and regulation of energy metabolism. Consistent with this notion, NKA $\alpha 1$ and Src were recently shown to play an important role in regulating mitochondrial respiration (Kutz et al. 2021).

In addition, ouabain was previously shown to increase glycogen synthesis in isolated skeletal muscles as well as cultured skeletal muscle cells (Clausen 1966; Kotova et al. 2006a, 2006b). Interestingly, in our current study a reduction in the lactate production, ECAR, and OCR as well as the FCCP-stimulated maximal OCR was not paralleled by alterations in the uptake of 2-DG. While we did not measure the glucose oxidation, these results showed that the net glucose uptake was unaltered, while glycolysis and OCR were reduced. Our results are therefore compatible with the possibility that ouabain may have redirected glucose towards glycogen synthesis in HK-2 cells.

Here we did not examine the functional consequences of the Tyr10 phosphorylation, but these may theoretically include modulation of NKA kinetics, protein-protein interactions with signalling proteins or NKA regulators, such as FXYD proteins, or NKA trafficking between the plasma membrane and the intracellular compartment. The ultimate effect of the tyrosine phosphorylation of NKA $\alpha 1$ is unclear since the studies which examined the functional significance of unspecific tyrosine phosphorylation or phosphorylation of Tyr10 did not produce consistent results. For instance, insulin and EGF increased tyrosine phosphorylation of NKA $\alpha 1$ and activity of NKA in rat proximal tubules (Feraille et al. 1999, 1997). In line with these findings, bromocriptine, a dopaminergic agonist, increased the membrane abundance of NKA $\alpha 1$, Tyr phosphorylation of NKA $\alpha 1$, and NKA activity in cultured rat proximal tubular cells (Narkar et al. 2002a, 2002b). Conversely, tyrosine phosphorylation of NKA $\alpha 1$ in epithelial cells of the lens suppressed NKA activity (Bozulic et al. 2004a, 2004b). Moreover, incubation of NKA isolated from the porcine kidney with dephostatin, an inhibitor of protein tyrosine phosphatases, reduced the NKA activity (El-Beialy et al. 2010). Similarly, in the rat diaphragm muscle eplerenone, an aldosterone receptor antagonist, reduced phosphorylation of Tyr10, while NKA activity was increased, suggesting Tyr10 is an inhibitory site (Breitenbach et al. 2016). Activation of Src family kinases and an increase in phosphorylation of Tyr10 in ocular ciliary epithelial cells was also suggested to mediate inhibition of NKA by nitric oxide (Shahidullah et al. 2014). It therefore appears that the functional consequences of the Try10 phosphorylation might differ across tissues.

\section{Conclusions}

In conclusion, AMPK activation suppressed the EGF-stimulated phosphorylation of Tyr10 in HK-2 cells, while NKA inhibitor ouabain promoted it. AMPK likely exerted this effect by suppressing the EGFR-Src pathway, but activation of tyrosine phosphatases, which dephosphorylate Tyr10 cannot be excluded. The mechanism by which ouabain enhanced the EGF-stimulated Tyr10 phosphorylation did not seem to involve altered signalling via EGFR or Src. Collectively, our results suggest a new mechanism by which AMPK regulates NKA, while highlighting a link between regulation of energy metabolism and NKA-mediated ion transport.

Acknowledgements Authors wish to thank to Professor Eric Féraille for thorough reading of the manuscript and for providing critical comments.

Author contributions SP and AVC conceptualized the study. SP planned the experiments, supervised the study, and prepared the first draft of the manuscript. MP prepared the first draft of the figures. All authors contributed to editing and (re)writing of the subsequent versions of the manuscript. MP, AV, KD, and KM performed the experiments. SP, MP, and AVC interpreted the data. All authors contributed to data analysis. 
Funding Open access funding provided by Karolinska Institute. MP, $\mathrm{AV}, \mathrm{KD}, \mathrm{KM}$ and SP were funded by the Slovenian Research Agency (grants \#P3-0043, \#J7-8276, \#J3-9263, \#J3-2523 and the young researcher grant to MP). SP and AVC are principal investigators of the bilateral cooperation project between Republic of Slovenia and the Russian Federation funded by the Slovenian Research Agency (BIRU/19-20-039). AVC is funded by the Swedish Research Council, the Novo Nordisk Research Foundation, the Strategic Research Programme in Diabetes at Karolinska Institutet, and the Russian Scientific Foundation (RNF \#19-15-00118). SP and KD were also supported by the COST Action CA15203 MitoEAGLE.

Data availability Original blots and PCR data files are available in the supplement to the manuscript.

\section{Declarations}

Conflict of interest There are no relevant conflicts of interest with regard to this study.

Ethical approval Not applicable. All experiments were done on commercially available cell cultures.

Open Access This article is licensed under a Creative Commons Attribution 4.0 International License, which permits use, sharing, adaptation, distribution and reproduction in any medium or format, as long as you give appropriate credit to the original author(s) and the source, provide a link to the Creative Commons licence, and indicate if changes were made. The images or other third party material in this article are included in the article's Creative Commons licence, unless indicated otherwise in a credit line to the material. If material is not included in the article's Creative Commons licence and your intended use is not permitted by statutory regulation or exceeds the permitted use, you will need to obtain permission directly from the copyright holder. To view a copy of this licence, visit http://creativecommons.org/licenses/by/4.0/.

\section{References}

Akiyama T, Ishida J, Nakagawa S, Ogawara H, Watanabe S, Itoh N, Shibuya M, Fukami Y (1987) Genistein, a specific inhibitor of tyrosine-specific protein kinases. J Biol Chem 262:5592-5595

Al-Khalili L, Krook A, Chibalin AV (2003) Phosphorylation of the $\mathrm{Na}+, \mathrm{K}+$-ATPase in skeletal muscle: potential mechanism for changes in pump cell-surface abundance and activity. Ann N Y Acad Sci 986:449-452

Aperia AC, Akkuratov EE, Fontana JM, Brismar H (2016) Na+, K+ATPase, a new class of plasma membrane receptors. Am J Physiol Cell Physiol 310:C491-495

Askari A (2019a) The other functions of the sodium pump. Cell Calcium 84:102105

Askari A (2019b) The sodium pump and digitalis drugs: Dogmas and fallacies. Pharmacol Res Perspect 7:e00505

Bagrov AY, Shapiro JI, Fedorova OV (2009) Endogenous cardiotonic steroids: physiology, pharmacology, and novel therapeutic targets. Pharmacol Rev 61:9-38

Benziane B, Bjornholm M, Pirkmajer S, Austin RL, Kotova O, Viollet B, Zierath JR, Chibalin AV (2012) Activation of AMP-activated protein kinase stimulates $\mathrm{Na}+, \mathrm{K}+$-ATPase activity in skeletal muscle cells. J Biol Chem 287:23451-23463

Biscardi JS, Maa MC, Tice DA, Cox ME, Leu TH, Parsons SJ (1999) c-Src-mediated phosphorylation of the epidermal growth factor receptor on Tyr845 and Tyr1101 is associated with modulation of receptor function. J Biol Chem 274:8335-8343

Blanco G, Mercer RW (1998) Isozymes of the Na-K-ATPase: heterogeneity in structure, diversity in function. Am J Physiol 275:F633-F650

Blaustein MP, Hamlyn JM (2020) Ouabain, endogenous ouabain and ouabain-like factors: The $\mathrm{Na}(+)$ pump/ouabain receptor, its linkage to NCX, and its myriad functions. Cell Calcium 86:102159

Bozulic LD, Dean WL, Delamere NA (2004a) The influence of Lyn kinase on $\mathrm{Na}, \mathrm{K}-\mathrm{ATPase}$ in porcine lens epithelium. Am J Physiol Cell Physiol 286:C90-C96

Bozulic LD, Dean WL, Delamere NA (2004b) The influence of protein tyrosine phosphatase-1B on Na, K-ATPase activity in lens. J Cell Physiol 200:370-376

Breitenbach S, Lehmann-Horn F, Jurkat-Rott K (2016) Eplerenone repolarizes muscle membrane through $\mathrm{Na}$, K-ATPase activation by Tyr10 dephosphorylation. Acta Myol 35:86-89

Buffin-Meyer B, Younes-Ibrahim M, Barlet-Bas C, Cheval L, Marsy S, Doucet A (1997) K depletion modifies the properties of Sch28080-sensitive K-ATPase in rat collecting duct. Am J Physiol 272:F124-F131

Carling D, Zammit VA, Hardie DG (1987) A common bicyclic protein kinase cascade inactivates the regulatory enzymes of fatty acid and cholesterol biosynthesis. FEBS Lett 223:217-222

Chibalin AV, Kovalenko MV, Ryder JW, Feraille E, Wallberg-Henriksson H, Zierath JR (2001) Insulin- and glucose-induced phosphorylation of the $\mathrm{Na}(+), \mathrm{K}(+)$-adenosine triphosphatase alphasubunits in rat skeletal muscle. Endocrinology 142:3474-3482

Clausen T (1966) The relationship between the transport of glucose and cations across cell membranes in isolated tissues. II. Effects of $\mathrm{K}+$-free medium, ouabain and insulin upon the fate of glucose in rat diaphragm. Biochim Biophys Acta 120:361-368

Clausen T, Van Hardeveld C, Everts ME (1991) Significance of cation transport in control of energy metabolism and thermogenesis. Physiol Rev 71:733-774

Cool B, Zinker B, Chiou W, Kifle L, Cao N, Perham M, Dickinson R, Adler A, Gagne G, Iyengar R, Zhao G, Marsh K, Kym P, Jung P, Camp HS, Frevert E (2006) Identification and characterization of a small molecule AMPK activator that treats key components of type 2 diabetes and the metabolic syndrome. Cell Metab 3:403-416

Corton JM, Gillespie JG, Hawley SA, Hardie DG (1995) 5-aminoimidazole-4-carboxamide ribonucleoside. A specific method for activating AMP-activated protein kinase in intact cells? Eur $\mathbf{J}$ Biochem 229:558-565

Craig WS, Kyte J (1980) Stoichiometry and molecular weight of the minimum asymmetric unit of canine renal sodium and potassium ion-activated adenosine triphosphatase. J Biol Chem 255:6262-6269

Davies SP, Sim AT, Hardie DG (1990) Location and function of three sites phosphorylated on rat acetyl-CoA carboxylase by the AMP-activated protein kinase. Eur J Biochem 187:183-190

de Diesbach P, Medts T, Carpentier S, D'Auria L, Van Der Smissen P, Platek A, Mettlen M, Caplanusi A, van den Hove MF, Tyteca D, Courtoy PJ (2008) Differential subcellular membrane recruitment of Src may specify its downstream signalling. Exp Cell Res 314:1465-1479

Dolinar K, Jan V, Pavlin M, Chibalin AV, Pirkmajer S (2018) Nucleosides block AICAR-stimulated activation of AMPK in skeletal muscle and cancer cells. Am J Physiol Cell Physiol 315(6):C803-C817

El-Beialy W, Galal N, Deyama Y, Yoshimura Y, Suzuki K, Tei K, Totsuka Y (2010) Regulation of human and pig renal $\mathrm{Na}(+)$, $\mathrm{K}(+)$-ATPase activity by tyrosine phosphorylation of their alpha(1)-subunits. J Membr Biol 233:119-126 
El Mernissi G, Doucet A (1984) Quantitation of [3H] ouabain binding and turnover of Na-K-ATPase along the rabbit nephron. Am J Physiol 247:F158-F167

Feraille E, Dizin E (2016) Coordinated control of ENaC and $\mathrm{Na}+, \mathrm{K}+$-ATPase in renal collecting duct. J Am Soc Nephrol 27:2554-2563

Feraille E, Doucet A (2001) Sodium-potassium-adenosinetriphosphatase-dependent sodium transport in the kidney: hormonal control. Physiol Rev 81:345-418

Feraille E, Carranza ML, Rousselot M, Favre H (1997) Modulation of $\mathrm{Na}+, \mathrm{K}(+)$-ATPase activity by a tyrosine phosphorylation process in rat proximal convoluted tubule. J Physiol 498(Pt 1):99-108

Feraille E, Carranza ML, Gonin S, Beguin P, Pedemonte C, Rousselot M, Caverzasio J, Geering K, Martin PY, Favre H (1999) Insulin-induced stimulation of $\mathrm{Na}+, \mathrm{K}(+)$-ATPase activity in kidney proximal tubule cells depends on phosphorylation of the alpha-subunit at Tyr-10. Mol Biol Cell 10:2847-2859

Ferrannini E (2017) Sodium-glucose co-transporters and their inhibition: clinical physiology. Cell Metab 26(1):27-38

Hanke JH, Gardner JP, Dow RL, Changelian PS, Brissette WH, Weringer EJ, Pollok BA, Connelly PA (1996) Discovery of a novel, potent, and Src family-selective tyrosine kinase inhibitor. Study of Lck- and FynT-dependent T cell activation. J Biol Chem 271:695-701

Hardie DG (2013) AMPK: a target for drugs and natural products with effects on both diabetes and cancer. Diabetes 62:2164-2172

Hardie DG (2018) Keeping the home fires burning: AMP-activated protein kinase. J R Soc Interface 15(138):20170774

Hawley SA, Ross FA, Chevtzoff C, Green KA, Evans A, Fogarty S, Towler MC, Brown LJ, Ogunbayo OA, Evans AM, Hardie DG (2010) Use of cells expressing gamma subunit variants to identify diverse mechanisms of AMPK activation. Cell Metab 11:554-565

Holthouser KA, Mandal A, Merchant ML, Schelling JR, Delamere NA, Valdes RR Jr, Tyagi SC, Lederer ED, Khundmiri SJ (2010) Ouabain stimulates Na-K-ATPase through a sodium/hydrogen exchanger-1 (NHE-1)-dependent mechanism in human kidney proximal tubule cells. Am J Physiol Renal Physiol 299:F77-90

Jhaveri TZ, Woo J, Shang X, Park BH, Gabrielson E (2015) AMPactivated kinase (AMPK) regulates activity of HER2 and EGFR in breast cancer. Oncotarget 6:14754-14765

Kajikawa M, Fujimoto S, Tsuura Y, Mukai E, Takeda T, Hamamoto Y, Takehiro M, Fujita J, Yamada Y, Seino Y (2002) Ouabain suppresses glucose-induced mitochondrial ATP production and insulin release by generating reactive oxygen species in pancreatic islets. Diabetes 51:2522-2529

Kotova O, Al-Khalili L, Talia S, Hooke C, Fedorova OV, Bagrov AY, Chibalin AV (2006a) Cardiotonic steroids stimulate glycogen synthesis in human skeletal muscle cells via a Src- and ERK1/2dependent mechanism. J Biol Chem 281:20085-20094

Kotova O, Galuska D, Essen-Gustavsson B, Chibalin AV (2006b) Metabolic and signaling events mediated by cardiotonic steroid ouabain in rat skeletal muscle. Cell Mol Biol (Noisy-le-grand) $52: 48-57$

Kutz LC, Cui X, Xie JX, Mukherji ST, Terrell KC, Huang M, Wang X, Wang J, Martin AJ, Pessoa MT, Cai L, Zhu H, Heiny JA, Shapiro JI, Blanco G, Xie Z, Pierre SV (2021) The Na/K-ATPase alpha1/ Src interaction regulates metabolic reserve and Western diet intolerance. Acta Physiol (Oxf) 232:e13652

Kyte J (1971) Purification of the sodium- and potassium-dependent adenosine triphosphatase from canine renal medulla. J Biol Chem 246:4157-4165

Lang F, Foller M (2014) Regulation of ion channels and transporters by AMP-activated kinase (AMPK). Channels (Austin) 8:20-28

Leonard AP, Cameron RB, Speiser JL, Wolf BJ, Peterson YK, Schnellmann RG, Beeson CC, Rohrer B (2015) Quantitative analysis of mitochondrial morphology and membrane potential in living cells using high-content imaging, machine learning, and morphological binning. Biochim Biophys Acta 1853:348-360

Mars T, Mis K, Meznaric M, Prpar Mihevc S, Jan V, Haugen F, Rogelj B, Rustan AC, Thoresen GH, Pirkmajer S, Nikolic N (2020) Innervation and electrical pulse stimulation-in vitro effects on human skeletal muscle cells. Appl Physiol Nutr Metab 46(4):299-308

Miller WT (2003) Determinants of substrate recognition in nonreceptor tyrosine kinases. Acc Chem Res 36:393-400

Morth JP, Pedersen BP, Toustrup-Jensen MS, Sorensen TL, Petersen J, Andersen JP, Vilsen B, Nissen P (2007) Crystal structure of the sodium-potassium pump. Nature 450:1043-1049

Narkar V, Hussain T, Lokhandwala M (2002a) Role of tyrosine kinase and $\mathrm{p} 44 / 42$ MAPK in $\mathrm{D}(2)$-like receptor-mediated stimulation of $\mathrm{Na}(+), \mathrm{K}(+)$-ATPase in kidney. Am J Physiol Renal Physiol 282:F697-702

Narkar VA, Hussain T, Lokhandwala MF (2002b) Activation of D2-like receptors causes recruitment of tyrosine-phosphorylated NKA alpha 1-subunits in kidney. Am J Physiol Renal Physiol 283:F1290-F1295

Ogawara H, Akiyama T, Ishida J, Watanabe S, Suzuki K (1986) A specific inhibitor for tyrosine protein kinase from Pseudomonas. J Antibiot (Tokyo) 39:606-608

Pirkmajer S, Kulkarni SS, Tom RZ, Ross FA, Hawley SA, Hardie DG, Zierath JR, Chibalin AV (2015) Methotrexate promotes glucose uptake and lipid oxidation in skeletal muscle via AMPK activation. Diabetes 64:360-369

Pirkmajer S, Bezjak K, Matkovic U, Dolinar K, Jiang LQ, Mis K, Gros K, Milovanova K, Pirkmajer KP, Mars T, Kapilevich L, Chibalin AV (2020) Ouabain suppresses IL-6/STAT3 signaling and promotes cytokine secretion in cultured skeletal muscle cells. Front Physiol 11:566584

Pirkmajer S, Petric M, Chibalin AV (2021) The role of AMPK in regulation of $\mathrm{Na}(+), \mathrm{K}(+)$-ATPase in skeletal muscle: does the gauge always plug the sink? J Muscle Res Cell Motil 42:77-97

Post RL, Jolly PC (1957) The linkage of sodium, potassium, and ammonium active transport across the human erythrocyte membrane. Biochim Biophys Acta 25:118-128

Rajani R, Pastor-Soler NM, Hallows KR (2017) Role of AMP-activated protein kinase in kidney tubular transport, metabolism, and disease. Curr Opin Nephrol Hypertens 26:375-383

Rajh M, Dolinar K, Mis K, Pavlin M, Pirkmajer S (2016) Medium renewal blocks anti-proliferative effects of metformin in cultured MDA-MB-231 breast cancer cells. PLoS ONE 11:e0154747

Ramakers C, Ruijter JM, Deprez RH, Moorman AF (2003) Assumption-free analysis of quantitative real-time polymerase chain reaction (PCR) data. Neurosci Lett 339:62-66

Rohas LM, St-Pierre J, Uldry M, Jager S, Handschin C, Spiegelman BM (2007) A fundamental system of cellular energy homeostasis regulated by PGC-1alpha. Proc Natl Acad Sci USA 104:7933-7938

Rolfe DF, Brown GC (1997) Cellular energy utilization and molecular origin of standard metabolic rate in mammals. Physiol Rev 77:731-758

Rossier BC, Baker ME, Studer RA (2015) Epithelial sodium transport and its control by aldosterone: the story of our internal environment revisited. Physiol Rev 95:297-340

Ruijter JM, Ramakers C, Hoogaars WM, Karlen Y, Bakker O, van den Hoff MJ, Moorman AF (2009) Amplification efficiency: linking baseline and bias in the analysis of quantitative PCR data. Nucleic Acids Res 37:e45

Ryan MJ, Johnson G, Kirk J, Fuerstenberg SM, Zager RA, TorokStorb B (1994) HK-2: an immortalized proximal tubule epithelial cell line from normal adult human kidney. Kidney Int $45: 48-57$ 
Schoner W, Scheiner-Bobis G (2007) Endogenous and exogenous cardiac glycosides: their roles in hypertension, salt metabolism, and cell growth. Am J Physiol Cell Physiol 293:C509-C536

Sen AK, Post RL (1964) Stoichiometry and localization of adenosine triphosphate-dependent sodium and potassium transport in the erythrocyte. J Biol Chem 239:345-352

Shahidullah M, Mandal A, Wei G, Delamere NA (2014) Nitric oxide regulation of $\mathrm{Na}$, K-ATPase activity in ocular ciliary epithelium involves Src family kinase. J Cell Physiol 229:343-352

Shen JJ, Zhan YC, Li HY, Wang Z (2020) Ouabain impairs cancer metabolism and activates AMPK-Src signaling pathway in human cancer cell lines. Acta Pharmacol Sin 41:110-118

Skou JC (1957) The influence of some cations on an adenosine triphosphatase from peripheral nerves. Biochim Biophys Acta 23:394-401

Skou JC (1998) Nobel Lecture. The identification of the sodium pump. Biosci Rep 18:155-169

Spector NL, Yarden Y, Smith B, Lyass L, Trusk P, Pry K, Hill JE, Xia W, Seger R, Bacus SS (2007) Activation of AMP-activated protein kinase by human EGF receptor 2/EGF receptor tyrosine kinase inhibitor protects cardiac cells. Proc Natl Acad Sci USA 104:10607-10612

Steinberg GR, Carling D (2019) AMP-activated protein kinase: the current landscape for drug development. Nat Rev Drug Discov $18: 527-551$
Sullivan JE, Carey F, Carling D, Beri RK (1994) Characterisation of 5'-AMP-activated protein kinase in human liver using specific peptide substrates and the effects of 5'-AMP analogues on enzyme activity. Biochem Biophys Res Commun 200:1551-1556

Tuomi JM, Voorbraak F, Jones DL, Ruijter JM (2010) Bias in the Cq value observed with hydrolysis probe based quantitative PCR can be corrected with the estimated PCR efficiency value. Methods 50:313-322

Wang J, Velotta JB, McDonough AA, Farley RA (2001) All human $\mathrm{Na}(+)-\mathrm{K}(+)$-ATPase alpha-subunit isoforms have a similar affinity for cardiac glycosides. Am J Physiol Cell Physiol 281:C1336-C1343

Wu SS, Yamauchi K, Rozengurt E (2005) Bombesin and angiotensin II rapidly stimulate Src phosphorylation at Tyr-418 in fibroblasts and intestinal epithelial cells through a PP2-insensitive pathway. Cell Signal 17:93-102

Xie Z, Askari A (2002) $\mathrm{Na}(+) / \mathrm{K}(+)$-ATPase as a signal transducer. Eur J Biochem 269:2434-2439

Publisher's Note Springer Nature remains neutral with regard to jurisdictional claims in published maps and institutional affiliations.

\section{Authors and Affiliations}

\section{Metka Petrič $^{1}$ (D) Anja Vidović ${ }^{1} \cdot$ Klemen Dolinar $^{1} \cdot$ Katarina Miš $^{1} \cdot$ Alexander V. Chibalin $^{2,3}$ (D) Sergej Pirkmajer $^{1}$ (D)}

1 Faculty of Medicine, Institute of Pathophysiology, University of Ljubljana, Ljubljana, Slovenia

2 National Research Tomsk State University, Tomsk, Russia
Department of Molecular Medicine and Surgery, Integrative Physiology, Karolinska Institutet, Stockholm, Sweden 